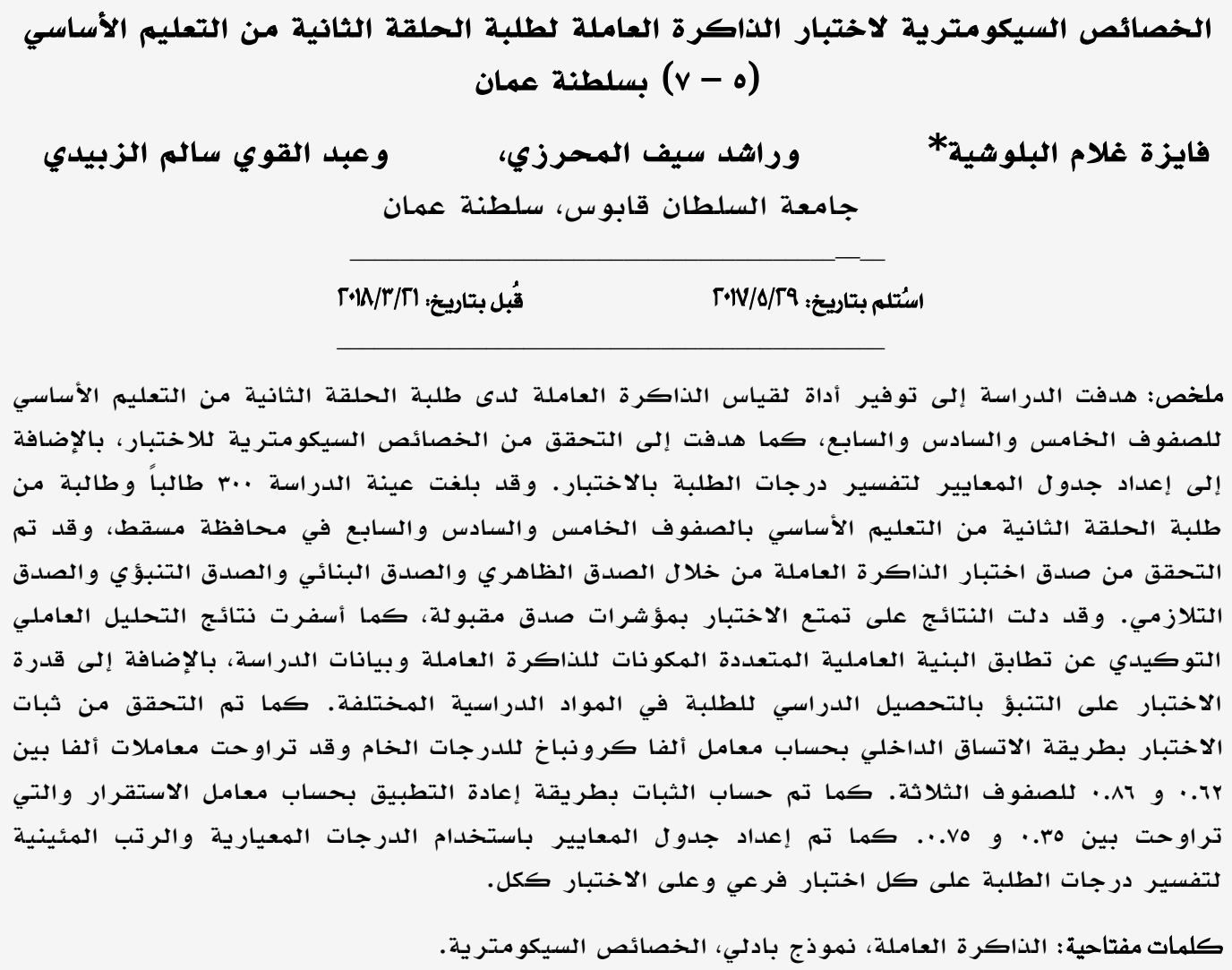

\title{
Psychometric Properties of Working Memory Test for Cycle Two (Grades 5-7) of Basic Education in Muscat Governorate in Oman
}

Faiza G. Albalushi*, Rashid S. Almehirzi, \& Abdulqawi S. Al Zubaidi Sultan Qaboos University, Sultanate of Oman

Abstract: The study aimed to develop a test to measure working memory for students in grades 5-7 in Basic Education and examine its psychometric properties. The study aimed also to develop the required norm scores for score interpretation. The sample consisted of 300 male and female students from grades 5,6 and 7 in Muscat governorate. The validity of the working memory test was examined through face validity, construct validity, predictive validity and concurrent validity. The results supported the validity of the test. Confirmatory factor analysis showed the fit of data to the factorial structure of the working memory. In addition, the test showed high predictive validity of student achievement for several subjects. The reliability of the test was examined using Cronbach alpha reliability and test-retest reliability. Cronbach Alpha reliability ranged between 0.62 and 0.86 for the three grades. Similarly, test-retest reliability was between 0.35 and 0.75 . The norm scores were computed using standardized scores and percentile ranks for each of the three subtests within each grade.

Keywords: Working memory, Baddeley model, psychometric properties.

*omsultannoor2012@outlook.com 
المعلومات السابق تخزينها أو الاحتفاظ بها لإنجاز

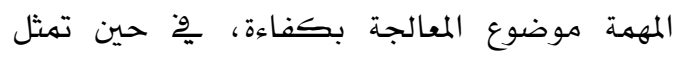
الذاكرة قصيرة المدى مكونا ذا سعة محدودة المعالجة لتجميع وحمل المعلومات الضرورية التي يستقبلها الفرد أثناء الحديث أو القراءة من أجل الاستهرار

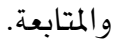

يذكر بادلي أن الذاكرة العاملة نظام ثلاثي

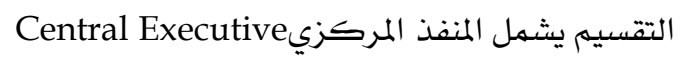
وهو بمثابة نظام رئيسي يسيطر رقابيا على عمليات

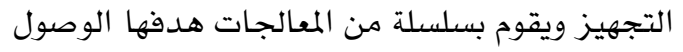
إلى الاستجابة الصحيحة، يعاونه نظامان تابعان، يخصص الأول لتجهيز المعلومات اللغوية أو اللفظية

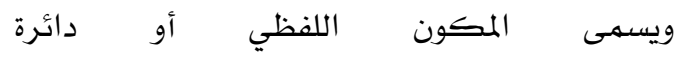
الملفوظPhonological Loop، ويخصص النظام الثاني لتجهيز الصور والمعلومات البصرية والمكانية، وإدراك العلاقات المكانية ويسهى المخطط البصري المكاني Visuospatial Sketchpad. وتعمل هذه المكونات بِّ آن واحد بِّ تكامل وانسجام تامين

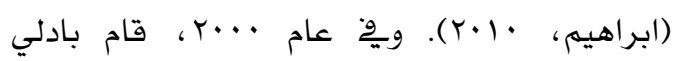
بإضافة مكون رابع جديد إلى المكونات الثلاثة السابقة يسهى الحاجز الاستطرادي العاده Buffer ، ويقوم هذا المكون بعملية الريط بين المهن النظامين التابعين للمنفذ المركزي (المخطط

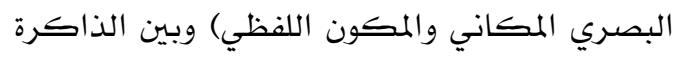

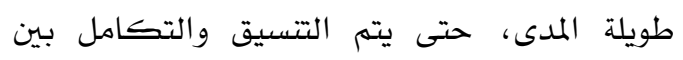
المعلومات الجديدة والمعلومات القديمة. ووِّْ ظل غياب أدوات القياس المحلية فلا مفر من

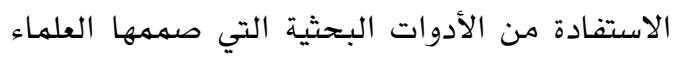

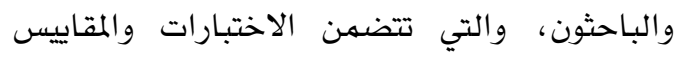
النفسية والتربوية. إن قضية تطوير الاختبارات

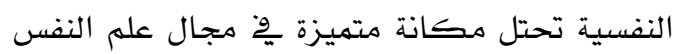
عامة، والقياس النفسي خاصة؛ حيث أن تقدم أي علم إنها يقاس بهدى قدرة هذا العلم على تقديم أدوات القياس وابتكارها، لذلك سعى علم النفس لنس

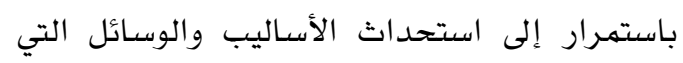

يعد مفهوم الذاكرة العاملة من المفاهيم المهمة بحّة

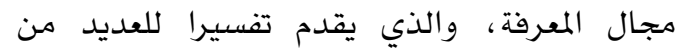

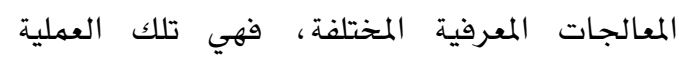
المسؤولة عن تخزين، ومعالجة المعلومات، كما أنها المسؤولة عن تتشيط المعلومات القديمة، وتحديثها

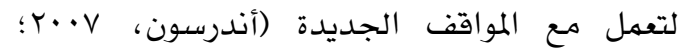
(Baddeley, (Alloway, 2007

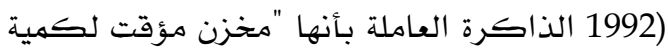
محدودة من المعلومات مع إمكانية تحويلها واستخدامها ِّْ إنتاج أو إصدار استجابات جديدة وذلك من خلال وجود مكونات مختلفة تقوم

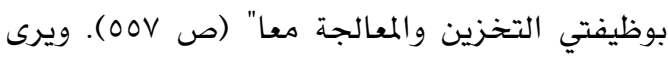
الزيات (1991) أن الذاكرة العاملة تهثل نظاما

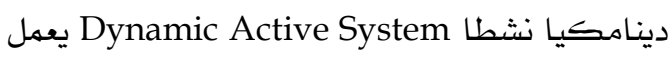
من خلال التركيز التزامني على كل من متطلبات التجهيز والتخزين، ومن ثم فالذاكرة العاملة هي مكون تجهيزي نشط ينقل أو يحول إلى الذاكرة طويلة المدى وينقل أو يحول منها. وتقاس فاعلية الذاكرة العاملة من خلال قدرتها على حمل كمية صغيرة من المعلومات حينما يتم تجهيز ومعالجة معلومات أخرى إضافية لتتكامل مع الأولى مكونة ما تقتضيه متطلبات الموقف، بينما تركز الذاكرة

$$
\text { قصيرة المدى على تخزين المعلومات. }
$$

ويعتبر نهوذج الذاكرة العاملة الذي قدمه "بادلي

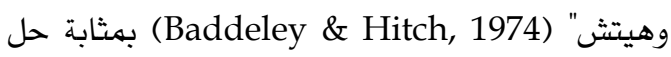
للتاقض الذي دام لفترات طويلة بين الباحثين بو

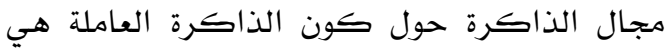
تفسها الذاكرة قصيرة المدى أم مكون مستقل عن الذاكرة قصيرة المدى، وقد أثبتت الدراسات

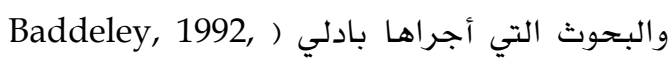

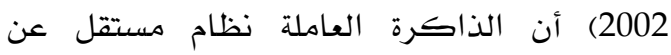
الذاكرة قصيرة المدى حيث لا تستطيع الذاكرة قصيرة المدى من القيام بالأدوار التي تقوم بها الذاكرة العاملة؛ حيث تهتم الذاكرة العاملة بتحليل

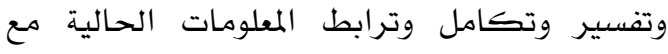


أما على الصعيد العربي فقد قام سليمان (•l. (ب) بتعريب، وتقنين البطارية الحاسوبية وِّ الذاكرة العاملة من إعداد ألواي (Alloway, 2007) على ولى

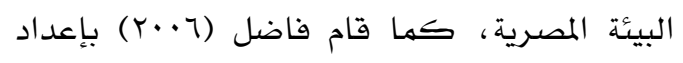
اختبارات الذاكرة العاملة لمرضى الفصام، والتي

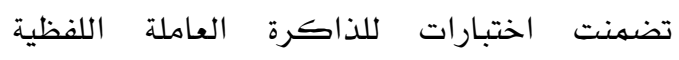
والذاكرة العاملة البصرية المكانية، وهذه

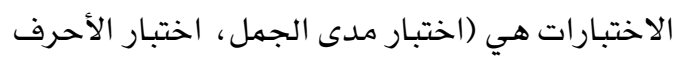
والأرقام، مكعبات كرسي، اختبار التعرف على الى

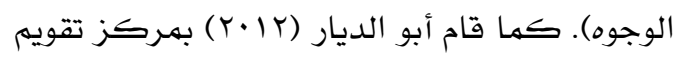
وتعليم الطفل بالكويت بتطوير اختبارات الذاكرة العاملة مقننة للأطفال، والذي يتكون من ستة

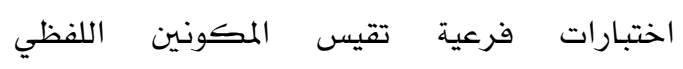

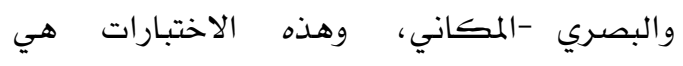
(الذاكرة المكانية التسلسلية، الذاكرة المكانية

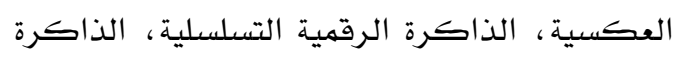

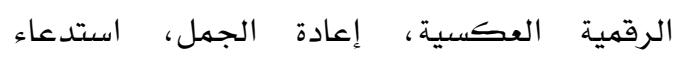
المستهوع). (لمعيه

وقد اهتمت العديد من الدراسات باكتشاف البنية العاملية للذاكرة العاملة وبناء اختبارات لقياسها

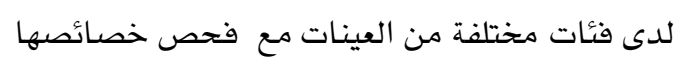

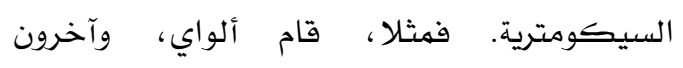
(Alloway et al., 2004)

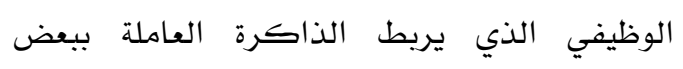
القدرات المعرفية (الوعي الصوتي، القدرات غير المير اللفظية) لدى الاطفال؛ حيث شملت عينة الدراسة

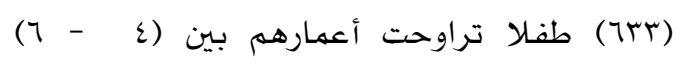

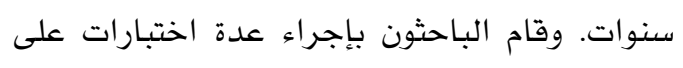
الاطفال منها اختبارات مدى الذاكرة والتي تضهنت

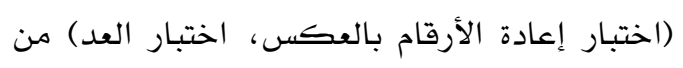

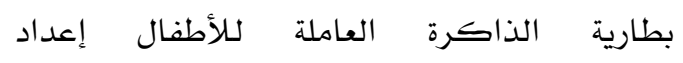
ل) ، بالاضافة لاختبار (إكمال الجمل، واستدعاء الكلمات الأخيرة) حيث يستهم الطفل لجملة تحتاج لإكمال

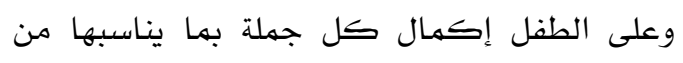
كلمات، وهن ثم استدعاء هذه الكلمات بنفس
يهكن الاعتماد عليها ِِّ قياس وتقنـين الكثير من مظاهر السلوك المختلفة؛ ويرجع ذلك لكون الكون الاختبارات النفسية هي من أهم الوسـائل المستخدمة وِّ مجال التقويم، الأمر الذي يتطلب تقنين أو إعداد وبناء اختبارات نفسية موثوقاً ِوِْ كفاءتها تستخدم

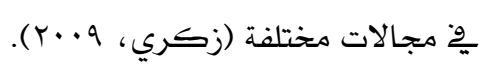
وقد اهتم الباحثون يِّ هذا المجال بالبحث والتقصي عن الأدوات التي تساعدهم پِّ قياس مكونات الذاكرة العاملة؛ حيث تهدف اختبارات الذاكرة العاملة إلى قياس القدرات المعرفية الأساسية للأفراد بناء على قياس مدى معالجة معلومات بسيطة

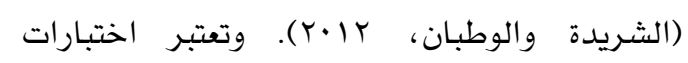

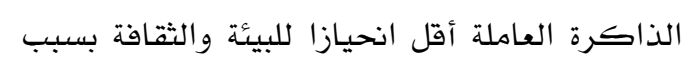
طبيعة البنية البسيطة لهذه الاختبارات وهذا يجعلها أقل اعتمادا على ثقافة الفرد. من هذه الاختبارات

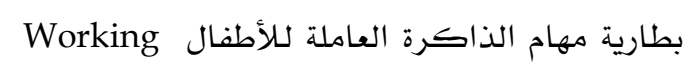
Memory Test Battery for Children من إعداد بيكرينج وجاثركول (WMTB-C) (Pickerin \& Gathercole, 2001) البطارية ثلاثة اختبارات لقياس المنفذ المركزي

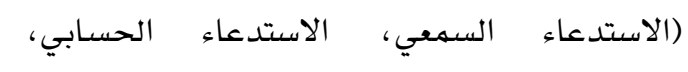
الاستدعاء العكسي للأرقام)، وأربعة اختبارات

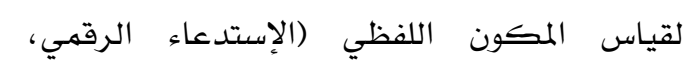
استدعاء قائمة الكلمات، استدعاء قائمة الكلمات عديمة المعنى، قائمة الكلمات المترابطة)، واختبارين لقياس المكون البصري -المكاني

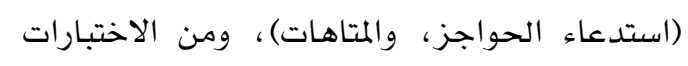

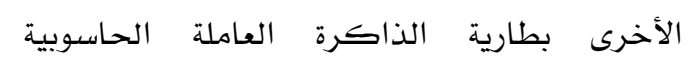
Automated Working Memory Assessment من إعداد ألواي (AWMA) مواي (Alloway, 2007)

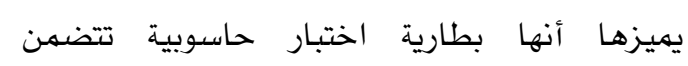
اختبارات لقياس مكونات الذاكرة العاملة

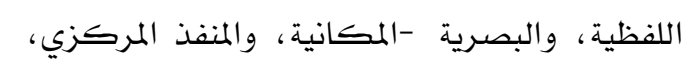

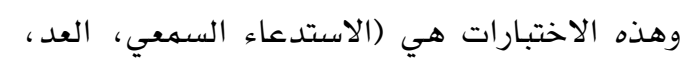

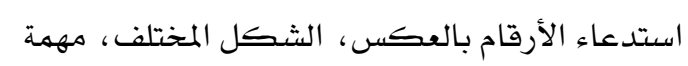

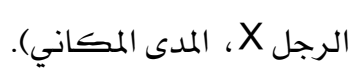


العاملة لدى الأطفال والمراهقين من ذوي الإعاقات الحسية المتوسطة، حيث شملت الدراسة (110) طفلا، متوسط أعمارهم (·) سنوات، و(91) مراهقا متوسط أعمارهم (10) سنة . طبقت

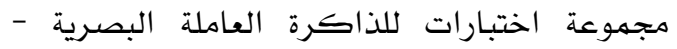
المكانية ، واختبارات أخرى للذاكرة قصيرة المدى، ألمبك، ويإجراء التحليل العاملي التوكيدي أشارت النتائج إلى أن نهوذج بادلي وهيتش للذاكرة العاملة لا لاكل

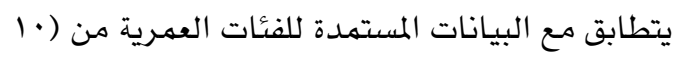
- 10) سنة، حيث له تحقق مؤشرات الملائمة حسن المطابقة للنموذج، كما تبين من تحليل المكونات الرئيسة وجود نسق كامن أشارت الى لى وجود عامل واحد عام للذاكرة العاملة.

وهدفت دراسة سليمان (•(†) إلى استكشاف الفروق بين الذكور والإناث وِّ الأداء على اختبارات الذاكرة العاملة، كما هدفت لاستكشاف مدى

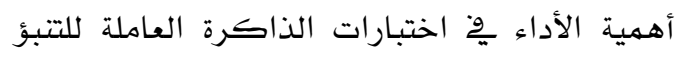
بالتحصيل الدراسي، وعلاقة العمر بالأداء على

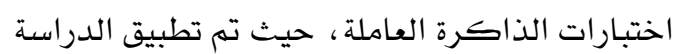
على عينة شملت (Y^T) طالبا وطالبة متوسط أعمارهم 1.9V سنة. استخدم الباحث البطارية الآلية للذاكرة العاملة إعداد (Alloway, 2007) والتي تشمل على اختبارات الذاكرة العاملة اللفظية وهي: (اختبار التذكر السهعي، اختبار العد، ، اختبار

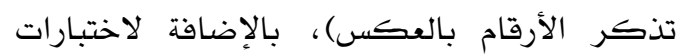
الذاكرة العاملة البصرية -المككانية والتي تتضهن الاختبارات التالية : (اختبار استدعاء الشكل المختلف، اختبار Mr.X، اختبار المدى المكاني)، وقد تحقق الباحث من الخصائص السيكومترية لهذه الاختبارات على عينة الدراسـة حيث استخدم الباحث الصدق التلازمي وذلك بحساب معامل الارتباط بين اختبارات الذاكرة العاملة ، واختبارات الذاكرة قصيرة المدى المتضهنة ِِّْ نفس البطارية، وقد تراوحت قيمة معاملات الارتباط بين الاختبارات

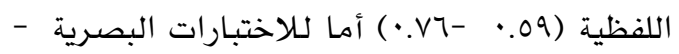

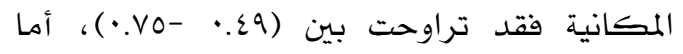
الثبات فقد حسبها الباحث بطريقة التجزئة النصفية
ترتيب عرض الجمل عليه، أها بالنسبة لاختبارات

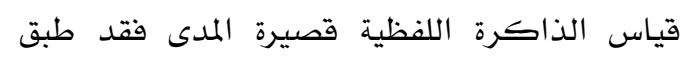

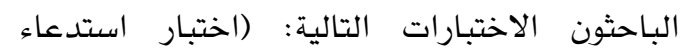

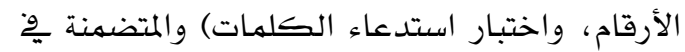
بطارية الذاكرة العاملة لكأطفال إعداد (Pickeoing \& Gathercole, 2001). وقد قام الباحثون بإجراء وتصميم عدة تصاميم لمطابقة البيانات مـع النموذج المناسب للذاكرة العاملة، ودراسة مؤشرات حسن مطابقة البيانات للنموذج، فكانت نتائج النموذج الأنسب تلك التي بنيت على نهوذج بادلي للذاكرة العاملة متعدد المكونات .(Baddeley, 2000) كما قام ألواي، وآخرون (Alloway et al., 2006) بإجراء دراسة بهدف دراسة البنية العاملية للذاكرة العاملة اللفظية والبصرية -المككانية لدى الأطفال بأعمار تتراوح بين (ع-11) سنة ، حيث شملت العينة على V·a طفلا وطفلة من المدارس الإبتدائية.

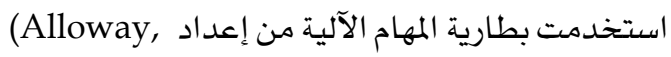
(2004، والتي اشتملت على ستة اختبارات لقياس مكونات الذاكرة العاملة اللفظية والبصرية - ماكية المكانية، وستة اختبارات أخرى لقياس سعة تخزين الذاكرة قصيرة المدى اللفظية والبصرية المكانية. تم التحقق من ثبات المقياس باستخدام طريقة إعادة التطبيق، والذي دل على عدم وجود اختحلاف دال

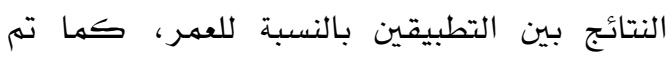
التحقق من الصدق العاملي للمقياس. وقد أسفرت

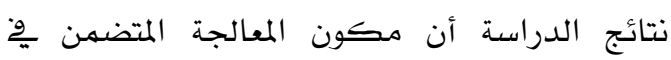
اختبارات الذاكرة العاملة كان مدعوما بعامل عام من موارد الذاكرة العاملة، بينما جوانب التخزين تعتمد على مصادر لفظية وبصرية - مكانية محدودة المجال، وأن هذا النموذج متسق بدرجة كبيرة خلال مرحلة الطفولة، كما دلت النتائج على ظهور تحسن ملحوظ ٍِِّ أداء الأطفال على مهام الذاكرة العاملة عبر الفئات العهرية، ولم تظهر مهر اختلاف بالنسبة للجنس. قام فان ديرمولن (Molen, 2010)، بإجراء دراسـة هدفت اختبار صحة نموذج بادلي وهيتش للذاكرة 
استخدمت طريقة الاتساق الداخلي عن طريق حساب معامل ألفا كرونباخ، وتراوحت القيم بين (rی. · - 97 • ) ، وتؤكد النتائج السابقة على تمتع البطارية بخصائص سيكومترية مقبولة ، كما أشارت نتائج الدراسة على وجود فروق دالة إحصائيا بين الفئات

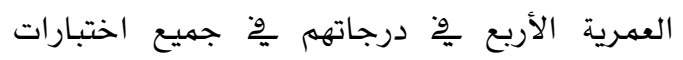

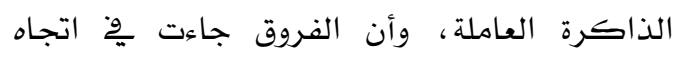

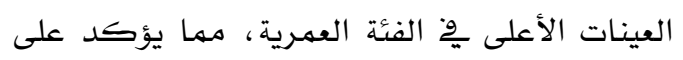
الطبيعة النمائية للذاكرة العاملة.

وهدفت دراسة كلا من جيفور وماليرلا وكورنولدي إلى (Giofre, Mammarella \& Cornoldi, 2013) استكشاف بنية الذاكرة العاملة وعلاقتها بالذكاء لدى الأطفال؛ حيث شملت عينة الدراسة الديه (IVT) والخامس بِّ المدراس الحسكومية متوسط أعمارهم (9.rV)

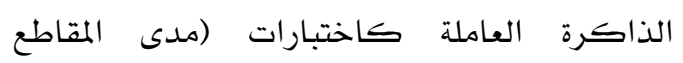
اللفظية ، ومدى الأرقام)، والتي استخدمت سـابقا مِّ دراسة سوانسون عام 1999 بالإضافة لاختبارات أخرى وهي (اختبار الاستهاع للكلمات، واختبار

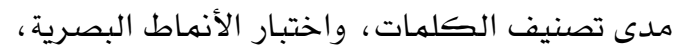

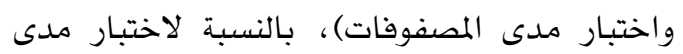
المصفوفات يعرض على الطالب بشكل محوسب ملب لمبل

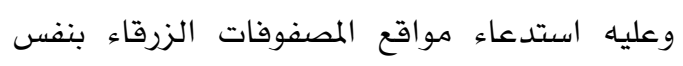
ترتيب عرضها عليه، وقد استخدم الباحثان التحليل العاملي التوكيدي لدراسة بنية الذاكرة العاملة وللحصول على مؤشرات حسن المطابقة مناسبة

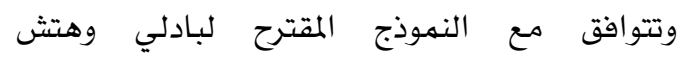
(Baddeley \& Hitch, 1997) للذاكرة العاملة، وقد أكدت جميع النتائج على مطابقة البيانات لنموذج بادلي متعدد المكونات.

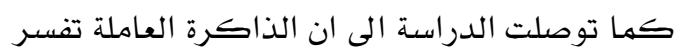

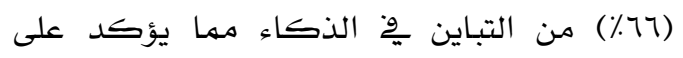
العلاقة بين الذاكرة العاملة والذكاء. أما دراسة الانصاري وسليمان (rا·باب) فقد هدفت لاختبار مـلائمة النموذج الثلاثي المكونات للذاكرة
عن طريق حساب معامـلات سبيرمان براون وقد

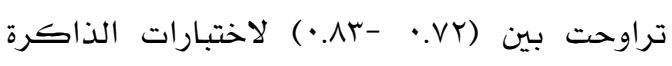
العاملة اللفظية وتراوحت بين (VV) - - - . • ) لاختبارات الذاكرة العاملة البصرية - -المكانية. توصلت الدراسة إلى وجود فروق بين الذكور والإناث ِِّْ الأداء على اختبارات الذاكرة العاملة لصالح الإناث يِّ المكونين، كما دلت النتائج على ولى أن الأداء ِِ2 اختبارات الذاكرة العاملة يرتبط ارتباطا موجبا بالعمر، وأن الأداء ينمو بوصفه دالة للعهر، كما أن الأداء وِّْ اختبارات الذاكرة العاملة يعد منبأ جيد للتحصيل الدراسي للطلبة؛ فقد توصلت الدراسة إلى وجود ارتباط دال وإيجابي بين

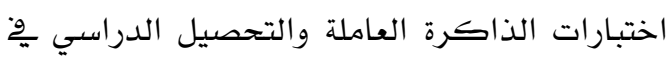

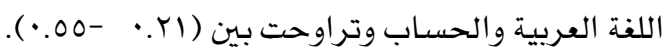
وقد أجرى الأنصاري وسليمان (rابץr) دراسـة هدفت لاستكشاف طبيعة أداء الأطفال الكويتين من الذكور والإناث عبر فئات عمرية تتراوح بين

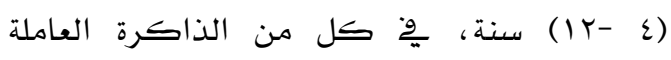
اللفظية والبصرية -المكانية، باستخدام بطارية اختبار حاسوبية أعدت بناء على نهوذج بادلي المتعدد

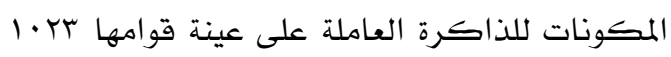
طفلا وطفلة من الكويتين، وقام الباحثان بحساب

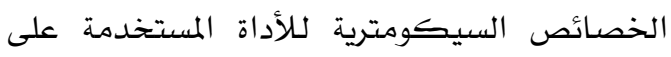
عينة قوامها ( ·.0). بالنسبة للصدق تم التحقق من صدق المفهوم باستخدام التحليل العاملي التوكيدي، حيث أشارت التحليلات إلى جودة ملاءمة البيانات للنهوذج المقترح ذي العاملين، كها تم التحقق من الصدق التقاربي للبطارية عن طريق حساب معامل الارتباط على مهام الذاكرة العاملة اللفظية ومهام الذاكرة العاملة البصرية -المكانية وبين عدد من المهام المعروفة للذاكرة العاملة (ذاكرة الجمل/ المدى البصري للأرقام/ مهمة ستروب)، ودلت النتائج على وجود ارتباطات إيجابية.

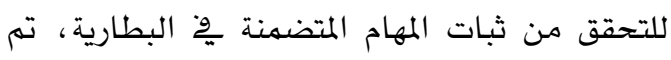
حساب الثبات بطريقة إعادة التطبيق، وتراوحت

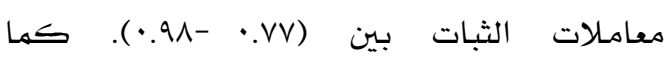


العاملة يخفقون عادة ِّْ مواجهة متطلبات أداء مواقف التعلم العرضي، وبذلك تتعطل العملية المتزايدة المتراكهة لاكتساب المعرفة عبر سنوات الدراسـة. فالطالب الذي لديه قصور ِّْ مهارات الذاكرة العاملة، يفشل وِّاستيعاب التعليمات التي يطلبها منه المعلم، ومن ثم يتخلف عن باقي زمـلائه.

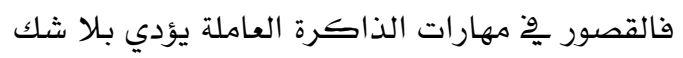

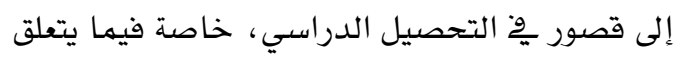

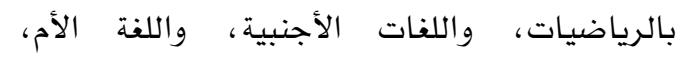
والقراءة ، والكتابة.

ومن خلال مراجعة الدراسـات وأدبيات البحث العلهي

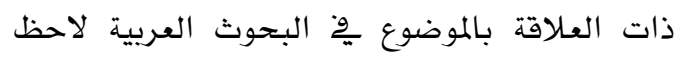
الباحثون وجود عدد من الدراسات التي تتاولت موضوع الذاكرة العاملة وعلاقتها بعدد من المتفيرات كالتحصيل الدراسي (محمد والثايب وصباح،

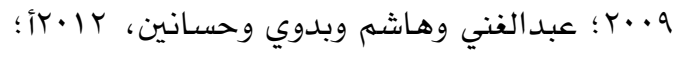

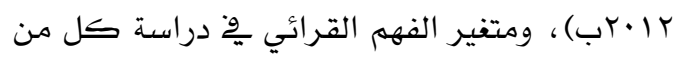

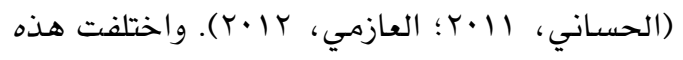
الدراسات بِ الاختبارات التي وضعت لقياس الذاكرة العاملة باختلاف الهدف من الدراسة فاهتم البعض بقياس المكون اللفظي فقط (الحساني،

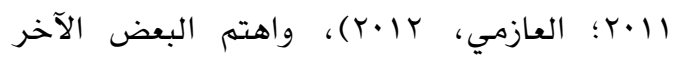
بقياس المكون البصري المكاني (محمد وآخرون،

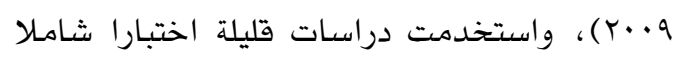
لقياس مكونات الذاكرة العاملة (الأنصاري

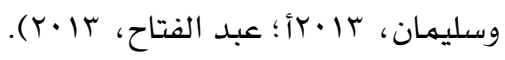

وقد لاحظ الباحثون من خلال الخبرة الميدانية ِِّ الحقل التربوي أن الطلبة يعانون پِّ مقاعد الدراسة

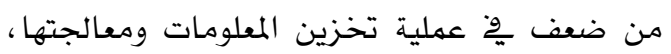
وخاصة لدى الطلبة ِِّ الصفوف الأولى من الحلقة الثانية من التعليم الأسـاسي (الصف الخامس إلى الصف العاشر)، ويظهر ذلك أثناء تتفيذ الأنشطة المعرفية المعقدة مثل: الفهم، والتخطيط، وحل المشكلات، وحل المسائل الحسابية، واتخاذ القرارات، وقد تستمر هذه المشككلات لدى بعض ولمل الطلبة خلال مراحل دراستهم المختلفة. ولقد تزايد
العاملة للبيانات المستمدة من تطبيق اختبار الذاكرة العاملة على أطفال كويتين، حيث شملت عينة الدراسة (191) من الأطفال تراوحت أعمارهـم بين

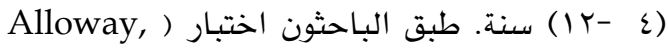
2007) لقياس مكونات الذاكرة العاملة اللفظية والبصرية - المككانية والمنفذ المركزي، حيث تقدم هذه الاختبارات بشكل محوسب، وباستخدام التحليل العاملي التوكيدي توصلت الدراسة إلى أدلة تدعم البنية الثلاثية للذاكرة العاملة حيث كانت مؤشرات الملائمة عند درجة القطع المطلوبة. وبناء على هذا التحليل قدم الباحثان أدلة على صدق التكوين الفرضي للاختبار، كما تم التحقق من الثبات بطريقة إعادة التطبيق وقد تراوحت المعامـلات

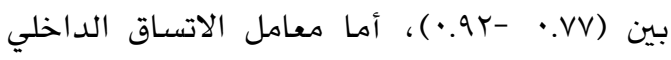
فقد تم حساب ألفا كرونباخ للاختبار ككل وكانت مساوية لـ(90.•) مما يشير بتمتع الاختبار بمعامل ثبات مرتفع، وقد توصلت نتائج الدراسـة إلى أدلة تدعم تكافؤ البنية العاملية الثلاثية المكونات

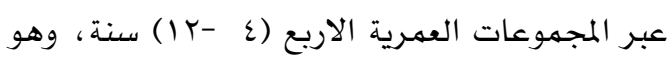
ما يشير إلى ثبات البنية العاملية الثلاثية لمكونات الذاكرة العاملة.

\section{مشكلة الدراسة، وأسئلتها}

تلعب الذاكرة العاملة دورا كبيرا ِّ2 عمليات تعلم الطلبة وِّ مختلف المراحل التعليمية. وتشير جاثركول (Gathercole, 2004) أن الذاكرة العاملة تعد مصدرا لتكامل المعرفة أو المعلومات من الذاكرة طويلة المدى مع المعلومات ِِّ المخزن الوقتي للذاكرة العاملة، ولذا فإن الفرد الذي يهتلك سعة المّل محدودة أو ضعيفة للذاكرة العاملة تصبح قدرته على تتفيذ تلك العملية محدودة ِّْ جميع الأنثطة داخل الفصل الدراسي، كما تشير إلى أن ضعف مهارات الذاكرة العاملة يتسبب ِِّ ضعف عملية التعلم أو ِِّ صعوبات ملحوظة ِِّ التعلم؛ لأن هذه المنظومة المعرفية تعد أساسية لتعلم العديد من

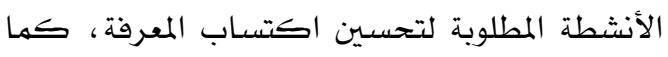
وجد سليمان (• (Y) أن الأفراد منخفضي الذاكرة 
1. ما مؤشرات صدق اختبار الذاكرة العاملة

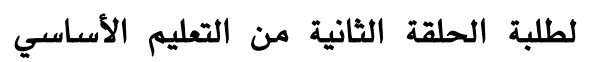

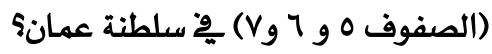

r. ما مؤشرات ثبات اختبار الذاكرة العاملة

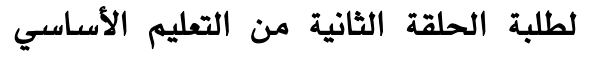

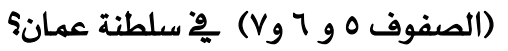

r. ما معايير تفسير درجات اختبار الذاكرة العاملة لطلبة الحلقة الثانية من التعليم

الأساسي (الصفوف 0 و 7 وV) ِِّ سلطنة

عمان؟

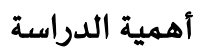

تستمد هذه الدراسة أهميتها من ضرورة توافر أداة

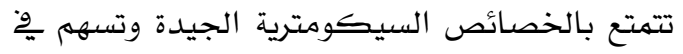
زيادة الدقة ِّْ تحديد مستوى الذاكرة العاملة

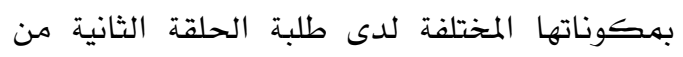
التعليم الأساسي (O - V)، كما تعد هذه الدراسة إضافة للدراسات والبحوث ِِّْ مقاييس الذاكرة العاملة، وتوفر اختبارا يمكن أن يستخدمها

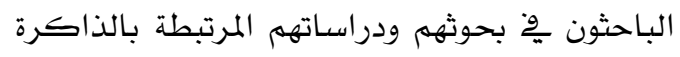
العاملة، وتكمن أهمية الدراسة من بهون الناحية

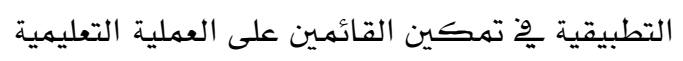
من تشخيص مكونات الذاكرة العاملة المختلفة لدى الطلبة، والتخطيط لإعداد التدريبات والأنشطة التعليمية المناسبة لتتمية مكونات الذاكرة العاملة.

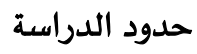

اقتصرت هذه الدراسة على بناء اختبار الذاكرة العاملة مكون من ثلاثة اختبارات فرعية خاصة بمكونات الذاكرة العاملة الثلاثة وهي (المكون اللفظي، والمكون البصري - المكاني، والمنفذ المركزي). كما اقتصر تطبيق هذه الدراسة على الى المري

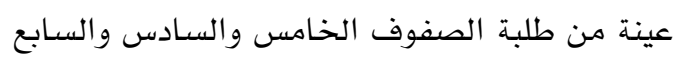
المقيدين بِّ مدارس الحلقة الثانية من التعليم الأساسي التابعة لمحافظة مسقط وِّ سلطنة عمان

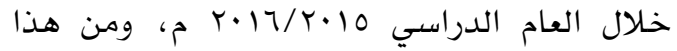

الاهتمام اليوم من قبل علماء النفس والباحثين بتقنين

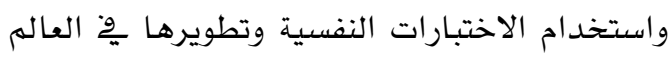

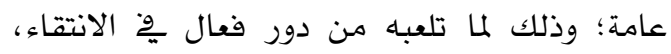

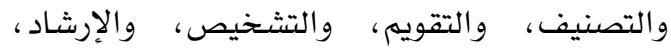
والتوجيه، والبحث العلهي، وِّ شتى المجالات التعليمية، والصناعية، والعسكرية. وقد تبلور هذا

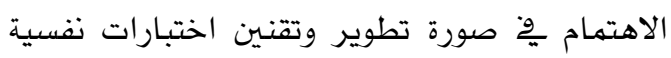
(راشد، ع ·r). لذا هناك حاجة لتوفير اختبارات

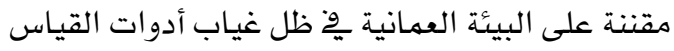
المحلية؛ كما هناك الحاجة للإستفادة من الأدوات البحثية التي صمهها العلماء والباحثين واستخراج

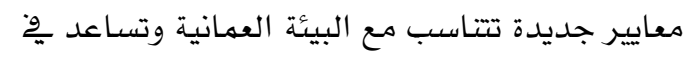
الكشف عن مستوى الطلبة وِّ المكونات المختلفة

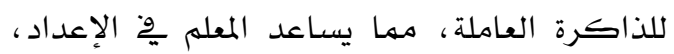

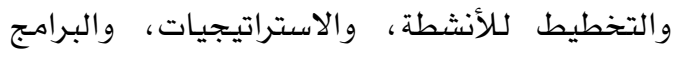
التدريبية المناسبة؛ وتتبنى هذه الاختبارات نهوذج

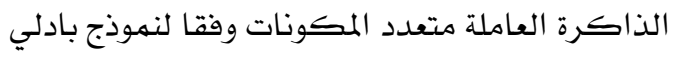

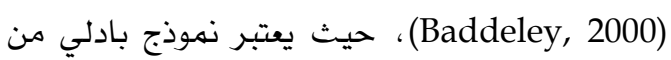

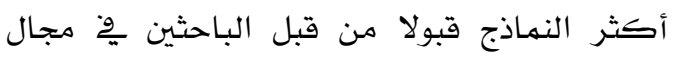

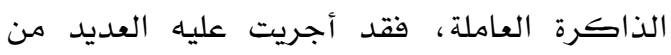
الدراسات للتحقق من صدق النموذج على عينات

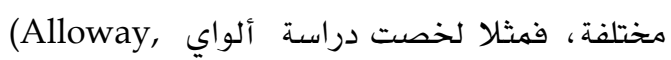

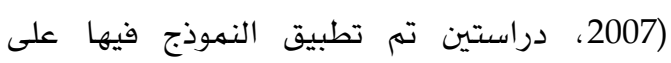

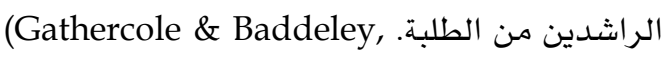
(Baddeley, 1996) (Alloway; ألواي وجاثركول وبيكرينج Gathercole \& Pickering, 2006) (Alloway; Gathercole; واثركول وويلز وأدامز

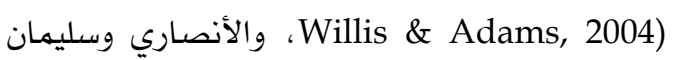
(rا •Yب) النموذج على عينات من الأطفال. هِّْ ضوء ما تقدم فإن الهدف الرئيسي من الدراسة يتمثل "ِّْ دراسة الخصائص السيكومترية لاختبار

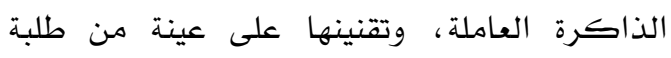
الصفوف الخامس والسادس والسابع من الحلقة التحانة

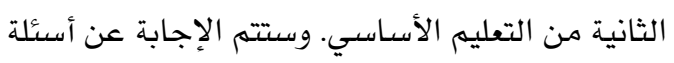

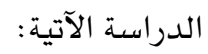




\begin{tabular}{|c|c|c|c|}
\hline \multicolumn{4}{|c|}{ خصائص عينة الدراسة وفقا للنوع } \\
\hline المجموع & \multicolumn{2}{|c|}{ النوع } & \multirow{2}{*}{ الصففو } \\
\hline & اناث & ذكور & \\
\hline $1 \ldots$ & 0. & 0. & الخامس \\
\hline $1 \ldots$ & 0. & 0. & السادس \\
\hline $1 \ldots$ & 0. & 0. & السابع \\
\hline$r .$. & 10. & 10. & المجموع \\
\hline
\end{tabular}

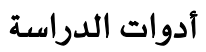

لتحقيق أهداف الدراسـة تم استخدام الأدوات الآتية: اختبار الذاكرة العاملة: تم إعداد هذا الاختبار من قبل الباحثين، ويقيس الاختبار مكونات الذاكرة العاملة لدى الطلبة من عمر (•1 - (1) سنة وفقا لنموذج بادلي ويتكون من ثلاثة اختبارات فرعية، وهي: اختبار المكون اللفظي للذاكرة العاملة، واختبار المكون البصري - المكاني للذاكرة العاملة، واختبار مكون المنفذ المركزي للذاكرة العاملة ، وفيما يلي وصف لكل اختبار.

\section{اختبار الذاكرة العاملة اللفظية (اختبار الاستدعاء} السمعي Listening Recall Test): يتكون الإختبار من أربعة مستويات، ويخٌ كل مستوى أريع مجموعات من الجمل بإجمالي (17) مجموعة من

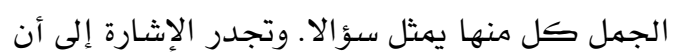
عدد الجمل يزداد عبر المستويات الأربعة. يتطلب هن الطالب الاستماع جيدا للجمل، والتفكير أولا بو الجمل هن حيث معناها إذا كانت صحيحة أم خاطئة ، ثم يذكر ثانيا آخر كلمة ذكرت فِّ كل جملة بنفس الترتيب الذي أعطيت لله الجمل. يرصد

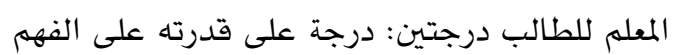
والحكم بصحة الجملة التي استمع إليها (الغرض من ذلك الوثوق من فهم الطالب وقدرته على إكمال الاختبار)، ودرجة على قدرة الطالب على استدعاء

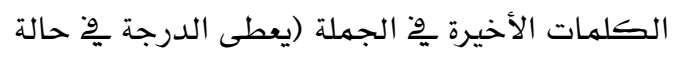
استدعاء الكلمات الأخيرة بنفس الترتيب المعطى فقط)، وتدخل الدرجة الثانية والتي تهثل قدرة الطالب على استدعاء الكلمة الأخيرة ِِّ حساب
المنطلق فإن إمكانية تعميم النتائج ترتبط بالحدود السابقة.

\section{الطريقة والإجراءات}

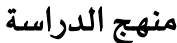

اعتمدت الدراسـة على المنهج الوصفي، نظرا لملاءمته لطبيعة الدراسـة وأهد افها؛ حيث يؤدي هذا المنهج إلى وصف الحالة، وتشخيصها، وتحليلها ، وتقسيرها بهدف اكتشاف العلاقات بين عناصرها أو بينها وبين الظواهر الأخرى، وذلك من خلال المعلومات التي تجمع عن الظاهرة.

\section{مجتمع الدراسة وعينتها}

شمل مجتمع الدراسـة جميع طلبة الحلقة الثانية من

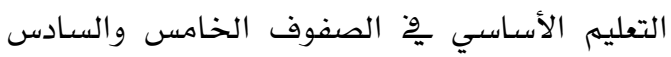
والسابع ِوْ المدارس الحكومية التابعة للمديرية العامة للتربية والتعليم بهحافظة مسقط، والبالغ عددهم (Y乏V9) طالبا وطالبة وفق آخر إحصائية

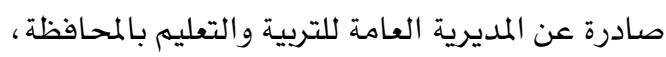
وقد تم اختيار عينة الدراسة وقوامها ..r طالب وطالبة بالطريقة العشوائية متعددة المراحل -Multi (stage) sampling ، حيث تم اختيار ولاية واحدة من ولايات محافظة مسقط كونها تشمل أكبر نسبة من الطلبة ، ثم تم اختيار أربع مدارس بطريقة

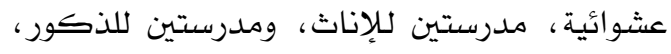
ومن ثم اختيار شعبة واحدة لكل صف من الصفوف (الخامس والسادس والسابع) بشكل عشوائي مِّ كل مدرسة من المدارس التي وقع عليها الاختيار، وذلك بحسب ظروف كل مدرسة وعدد الشعب المتوفرة، وبها أن عدد الطلبة المقيدين بالشعبة الواحدة يتراوح بين ro ro و.r طالبا ، تم اختيار طالبا من كل صف بطريقة عشوائية ، وقد تكونت عينة الدراسة من الطلبة العمانيين الذين تتراوح أعمارهم بين (· - (1) سنة ، والمقيدين بالصفوف خامس، وسـادس، وسـابع من المدارس المشهولة ِِ2 الدراسة، ، ويوضح الجدول (1) خصائص عينة الدراسـة وفقا للنوع والصف. 
(Y•l•) الصدق التلازمي لاختبار الذاكرة العاملة المعد هِ

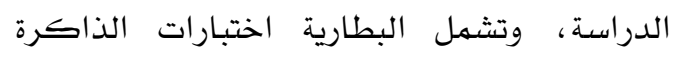
العاملة اللفظية وهي (التذكر السهعي، العد، تذكر الأرقام بالعكس)، واختبارات الذاكرة العاملة البصرية - المكانية وهي (استدعاء الشكل المختلف، Mr.X، المدى المكاني). تتمتع

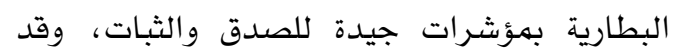

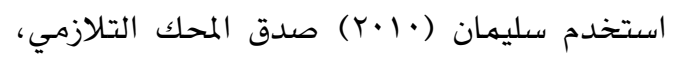
حيث طبق ستة اختبارات أخرى تقيس الذاكرة

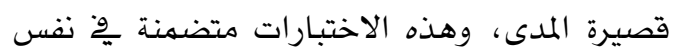
البطارية وهي اختبارات الذاكرة قصيرة المدى

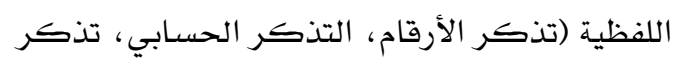
الكلمات)، بالإضافة لاختبارات الذاكرة قصيرة المدى البصرية -المكانية (المتاهات، مصفوفة النقاط، تذكر الكلمات المبهمة). وجاءت النتائج

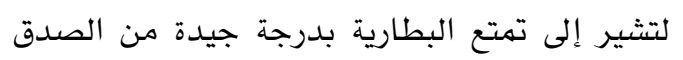
حيث تراوح معامل الارتباط لاختبارات الذاكرة

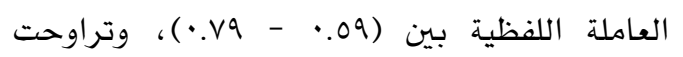

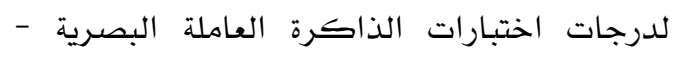

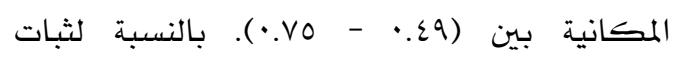

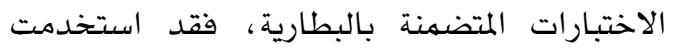

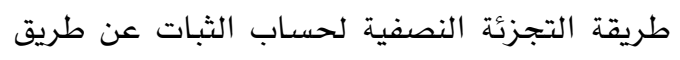
حسـاب معامـلات سبيرمان براون، وقد تراوحت بين

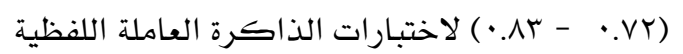
وتراوحت بين (VV). - - . . • لاختبارات الذاكرة

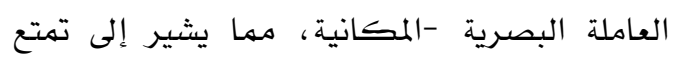
البطارية بدرجة عالية من الثبات.

\section{إجراءات الدراسة}

أولا: إجراءات بناء أداة الدراسة: وفيما يلي وصف

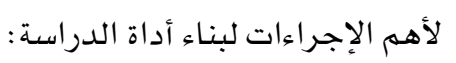

1. مراجعة الأدب النظري، والدراسـات السـابقة

التي تتاولت موضوع الذاكرة العاملة وفقا

لنموذج بادلي، وتحليل الاختبارات الواردة ـوِ

الدراسات السابقة بهدف تحديد الاختبارات

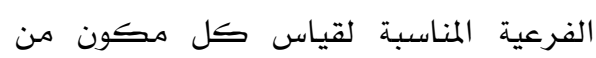

مستوى المكون اللفظي، ويتم حسـاب مجموع هذه الدرجات والتي تتراوح بين · -7 الدرجة.

اختبار الذاكرة العاملة البصرية - المكانية (اختبار الشكل المختلف Odd- One- Out Test ) : يتكون الاختبار من ستة مستويات، وبكل مستوى

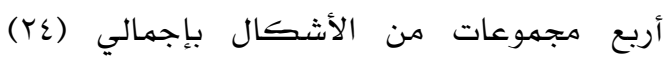
مجموعة من الأشكال كل منها يهثل سؤالا، ويجدر ذكره أن عدد الأشكال بكل مجموعة من الكول يزداد عبر المستويات الستة. يطلب من الطالب التعرف على الشكل المختلف، وِوِ نفس الوقت عليه تحديد موقعاه عندما تعرض عليه جداول فارغة. يرصد المعلم للطالب درجتين: درجة على هوفيل قدرته على التعرف على استدعاء الشكل المختلف لئل (بفرض الوثوق من فهم الطالب وقدرته على إكمال الاختبار)، ودرجة عند استدعائه مواقع الأشكال المختلفة التي عرضت عليه). ويتهم حساب مجموع درجات استدعاء مواقع الأشكال المختلفة والتي تتراوح بين · -ع درجة.

اختبار الذاكرة العاملة المنفذة مركزيا (اختبار لون الحبر Ink Colour Recall Test) يتكون الاختبار من ستة مستويات، بكل مستوى أربع مجموعات

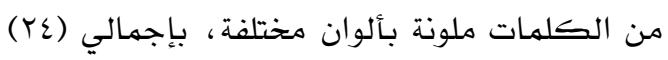
مجموعة من الكلهات تهثل كل منها سؤالا، يعرض على الطالب كلمات ملونة بلون حبر معين (الأحمر، الأزرق، الأخضر)، ويطلب منه أن يقراً الكلمات يٌْ كل مجموعة ، ومن ثم استدعاء لون حبر الكلمات التي قرأهـا بعد اخفاءها عنه. يرصد المعلم درجة للطالب عند قيامه باستدعاء ألوان حبر الكلمات التي عرضت عليه بنفس تسلسل العرض، ويعد مجموع هذه الدرجات درجات الاستدعاء والتي

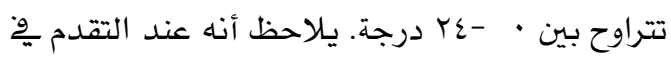

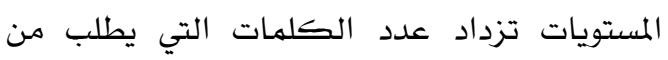
الطالب أن يتعرف على لون الحبر التي كتبت به، ويستدعيها بنفس تسلسل عرضها عليه.

بطارية الذاكرة العاملة الآلية للأطفال إعداد ألووي (Alloway, 2007)، وقام بتعريبه وتقنينه سليمان 
متوسط الزمن المستغرق لتطبيق الاختبار ككل لكل صف من الصفوف الثلاثة، حيث كان متوسط زمن التطبيق للصف

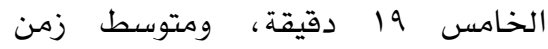
التطبيق للصف السادس وللصف السابع •r دقيقة ، ويرجع سبب زيادة زمن تطبيق

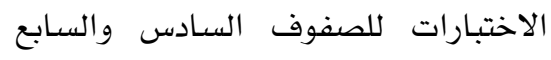
كون أن الطلبة يتقدمون لمستويات متقدمة أكثر من الصف الخامس الذين

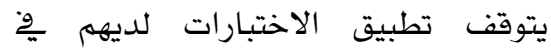

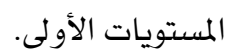

التأكد من المؤشرات السيكومترية الأولية لللأداة؛ وذلك بغرض التأكد

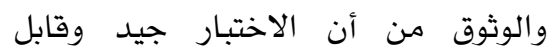
للتطبيق، حيث تم حساب معامل الثبات باستخدام معادلة ألفا كرونباخ كمؤشر على الاتساق الداخلي للاختبارات المطبقة

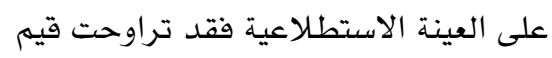

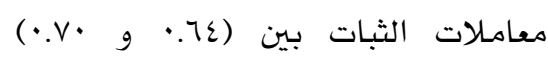
بالنسبة للاختبارات الفرعية، أما للاختبار ككل فقد كانت قيمة معامل الثبات

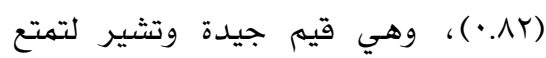
البطارية بقيم ثبات مناسبة. حساب معامل صعوبة الأسئلة، حيث تتراوح قيمة معامل الصعوبة بين (• - (1)، وقد تم تقديرها بنسبة عدد الذين أجابوا عن السؤال إجابة صحيحة، وقد كانت

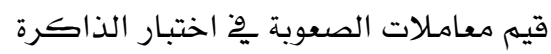

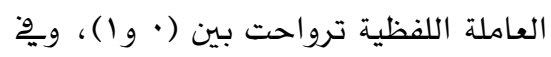

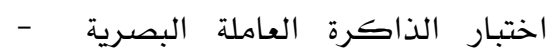
المكانية تراوحت بين (V•. و ) )، وبو

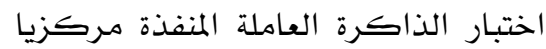

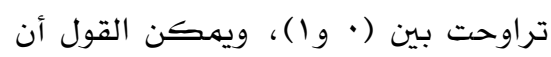

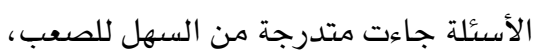
وهذا ما هدف إليه عند بناء الاختبارات،

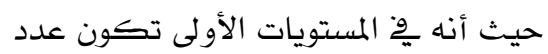

$$
\begin{aligned}
& \text { مكونات الذاكرة العاملة، وتحديد }
\end{aligned}
$$

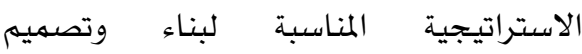

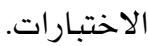

ז. البدء بكتابة وصياغة أسئلة الاختبار تبعا

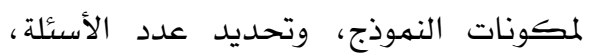

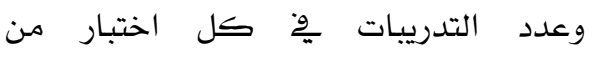
الاختبارات الفرعية. r. بعد إعداد النسخة الأولية من الاختبارات، تم عرضها على المحكهين المختصين بِّ مجال القياس والتقويم النفسي، وعلم النفس التربوي، وٌِّ مجال التربية الخاصة، وذلك النكائ للتأكد من وضوح تعليمات كل اختبار،

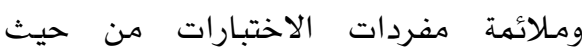
وضوحها وسلامتها اللغوية، وارتباط كل مفردة بالمكون الذي يقيسه. وقد تم تعديل النسخة الأولية وفقا لتوصيات المحكهين، لهنهان حيث تم حذف وتغيير جمل ٌِّ اختبار الذاكرة العاملة اللفظية، وتعديل بعض جلفيرل

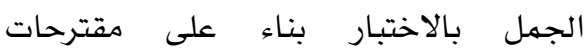

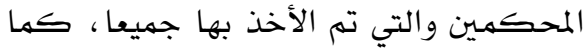
تم تغيير بعض الأشكال باختبار الذاكرة العاملة البصرية - المكانية. ع. طباعة النسخة المعدلة من الاختبار، وتطبيق النسخة المعدلة من الاختبارات على عينة استطلاعية مكونة من (·r) طالبا وطالبة تم اختيارهم بطريقة عشوائية من مدرستين أحدهما مدرسة إناث و والأخرى مدربة من مدرسة ذ كور ، وذلك بغرض:

التأكد من وضوح تعليمات الاختبار والأسئلة، وقد أشارت النتائج إلى وضوح تعليهات الاختبار ، وتمكن الطلبة من فهم المطلوب منهم لكل اختبار من الاختبارات الثلاثة. - ماثل

تحديد الزمن المستغرق للتطبيق لكل صف من الصفوف الثلاثة: تم حساب 
r. إجراء تعديلات على الاختبار وفقا لنتائج الدراسة الاستطلاعية.

ع. تدريب معلهي صعوبات التعلم بالمدارس التي وقع عليها الاختيار على أداة الدراسة، وذلك هلك للمساعدة پوْ تطبيق الإختبارات، حيث إن الإختبارات فردية ويستغرق تطبيقها زمنا لكل طالب، وتم التأكيد عليهم بضرورة التقيد بتعليمات كل اختبار عند التطبيق. ه. تطبيق الاختبارات بصورتها النهائية على عينة

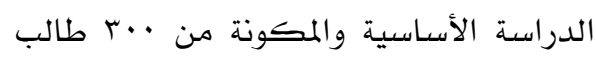
وطالبة من الصفوف الخامس والسـادس وله والسـابع خلال الفصل الدراسي الأول من العام

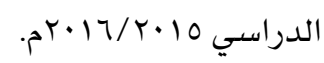

7. تطبيق بطارية الذاكرة العاملة لسليهان

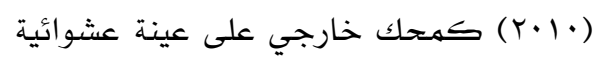
من العينة الأساسية ، تكونت من (•ع) طالبا

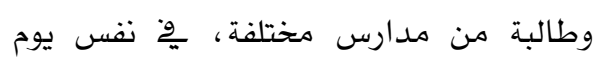
تطبيق أداة الدراسة بفاصل زمني قدره نصف ساعة ، وذلك بغرض حساب الصدق التلازمي. V. تحليل البيانات المجمعة للإجابة عن أسئلة

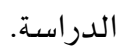

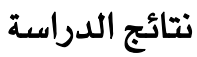

نتائج السؤال الأول/ ما مؤشرات صدق اختبار الذاكرة العاملة لدى طلبة الحلقة الثانية من التعليم الأساسي (V- O) بسلطنة عمان؟ وقد تم توظيف أربعة مؤشرات لصدق اختبار الذاكرة العاملة وهي لهي لهدي الصدق الظاهري، والصدق البنائي، والصدق

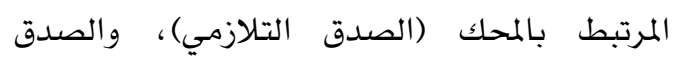
التتبؤي.

الصدق الظاهري (Face Validity):

تم التحقق من هذا النوع من الصدق من خلال عرض

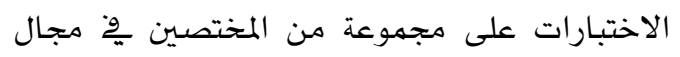

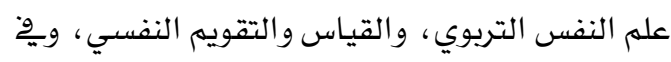
مجال التربية الخاصة بجامعة السلطان قابوس
المفردات المطلوب استدعاؤها قليل ويزداد بزيادة التدرج يخ المستويات وبالتالي يصعب على الطالب استدعاءهـا. 0. حساب معامل تمييز الأسئلة، وقد تم تقدير معامل التمييز بالفرق بين نسبة عدد الإجابات

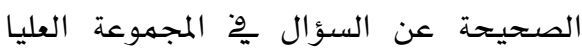
ونسبة عدد الإجابات الصحيحة ِوْ المجموعة الدنيا، وقد كانت جميع معامـلات التمييز لفقرات الاختبار وّ الاختبارات الفرعية

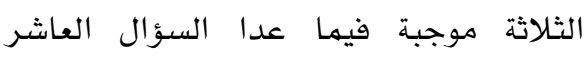

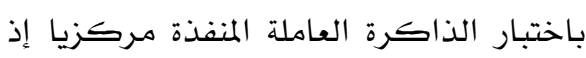

$$
\text { كانت القيمة سالبة ( - با. • ). }
$$

إجراء التعديلات التلازمة على الاختبار يو ضوء نتائج الدراسة الاستطلاعية ، وقد تم تعديل السؤال العاشر باختبار الذاكرة العاملة المنفذة مركزيا وذلك لأن معامل تمييزه جاء سالبا ، كما تم حذف الأسئلة

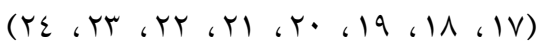
باختبار الذاكرة العاملة اللفظية، حيث تكون من ع ب سؤالا ِّ نسخته الأولى وكانت هذه الأسئلة تمثل المستويين الأخيرين (الخامس والسـادس) باختبار الذاكرة العاملة اللفظية. وتم حذف هذه الأسئلة بسبب عدم تمكن جميع الطلبة من الإجابة الصحيحة عليها. وبالتالي أصبح اختبار الذاكرة العاملة اللفظية يتكون من أربعة مستويات فقط ويشمل احل

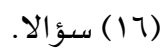
طباعة النسخة النهائية من الإختبار، وتعليمات التطبيق، وإعداد مفتاح تصحيح للهعلم، لرصد الدرجات بشكل مباشر

$$
\text { أثناء تطبيق الاختبارات. }
$$

\section{ثانيا : إجراءات تطبيق أداة الدراسة}

$$
\text { ا. بناء اختبارات الذاكرة العاملة. }
$$

ץ. إجراء الدراسة الاستطلاعية المذكورة سـابقا. 
Confirmatory التحليل العاملي التوكيدي Factor Analysis (CFA) AMOS

Maximum Likelihood التحليل من التأكد من مدى مطابقة البنية العاملية للاختبار ِِّ ضوء الإطار المفاهيهي لنهوذج بادلي

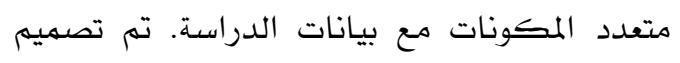
نهوذج التحليل العاملي التوكيدي بحيث يتكون من ثلاثة أبعاد، والتي تمثل الاختبارات الثلاثة

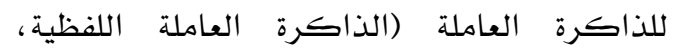
الذاكرة العاملة البصرية - المكانية، الذاكرة العاملة المنفذة مركزيا). وعند تصميم هذا النموذج المره روعي أن تحتفظ هذه الأبعاد بالارتباطات فيما بينها ، وبحيث تعمل هذه الأبعاد الثلاثة كمتغيرات مكونة لمتغير كامن هو الذاكرة العاملة. ونظرا لأن أسئلة الاختبار ثنائية التصحيح (صفر وواحد)، تم استخدام درجات الطلبة وِّ مستويات كل مكون كمتفيرات مشاهدة ِّ التحليل العاملي التوكيدي لتتحول الدرجات إلى متغيرات متصلة ومتعددة الدرجات. اشتهل البعد الأول على أربعة مستويات لأسئلة الذاكرة العاملة اللفظية، واشتهل البعد الثاني على ستة مستويات لأسئلة الذاكرة

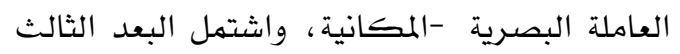

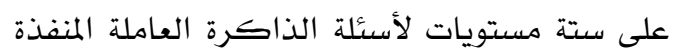
مركزيا.
وجامعة نزوى، وذلك لاستطلاع آرائهم حول مدى تمى وضوح تعليمات كل اختبار، وارتباط كل مفردة بالمككون الذي يقيسـه، وملائمة مفردات الاختبارات من حيث وضوحها وسـلامتها اللغوية، وقد اتفق المحكمون على وضوح تعليمات الاختبارات، ومناسبة الاختبارات الفرعية الثلاثة وِّو قياس مكونات الذاكرة العاملة. فقد تراوحت نسبة اتفاق

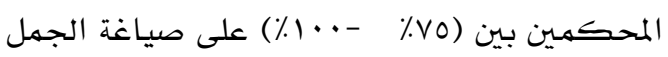
بالمستويات الأربعة وِّ اختبار الذاكرة العاملة اللفظية، مع اقتراح بعض التعديلات، والتي تم الأخذ بها. كما تراوحت نسب اتقاق المحكهـين يِّ اختبار الذاكرة العاملة البصرية - المكانية بين

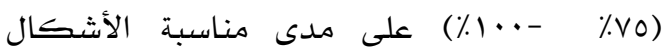
المتضهنة بالإختبار. وتراوحت نسب اتفاقهم مِ

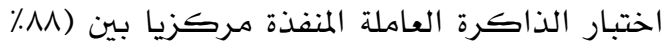

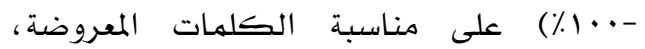
والألوان المستخدمة، وقد تم الأخذ بإقتراحات

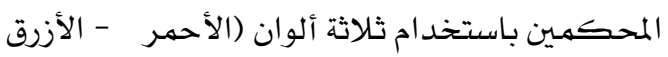
- الأخضر) وعدم استخدام اللون الأصفر حيث يصعب على الطلبة قراءة الكلمات بهذا اللون.

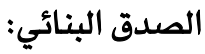
صدق البناء العاملي (Factor Analysis): تم التحقق من البنية العاملية لاختبار الذاكرة

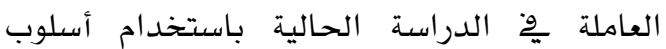

جدول r

نتائج مؤشرات حسن مطابقة النموذج التوكيدي لاختبار الذاكرة العاملة والقيم الحرجة المناظرة لها.

\begin{tabular}{|c|c|c|c|}
\hline القيمة الحرجة & قيمة المؤشر & المؤشر & 5 \\
\hline أقل من ه &. $.1 \varepsilon$ & $\begin{array}{r}\text { اختبار مربع كاي النسبي } \\
\text { Chi-Square/ df }\end{array}$ & 1 \\
\hline أقل من أو يساوي ^^... & $\cdots \cdot$ & $\begin{array}{r}\text { الجذر التربيعي لمتوسطات مربعات خطأ التقارب } \\
\text { Root Mean Square Error of } \\
\text { Approximation (RMSEA) }\end{array}$ & r \\
\hline 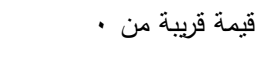 & $\cdots 11$ & $\begin{array}{r}\text { الجذر التربيعي لمتوسطات مربعات الخطأ التقاربي } \\
\text { (Standatdized RMR) }\end{array}$ & $r$ \\
\hline أكبر من أو يساوي • 9. . & -.99 & $\begin{array}{r}\text { مؤشر المطابقة المقارن (CFI) } \\
\text { Comparative Fit Index }\end{array}$ & $\varepsilon$ \\
\hline أكبر من أو يساوي • 9.. & $\because \vee \vee 9$ & $\begin{array}{r}\text { مؤشر المطابقة المعياري } \\
\text { Normed Fit Index (NFI) }\end{array}$ & 0 \\
\hline أكبر من أو يساوي •9.. & $\therefore$ vo & $\begin{array}{r}\text { مؤشر الملائمة الإضافي } \\
\text { Incremental Fit Index (IFI) }\end{array}$ & 7 \\
\hline
\end{tabular}


السبابع عْ الاختبارات الفرعية الثلاثة. وتظظهر المتوسطات الحسابية لمكونات الذاكرة العاملة في كل من عينة الذكور وعينة الاناث ارتفاعا تدريجيا مع الانتقال للأعلى يخّ الصفوف الدراسية. وتقدم هذه من النتائج مؤشـرا على الصدق البنائي لاختبارات الذاكرة العاملة يُّعلاقتها بالصفوف الدراسية. جدول ra

قيم التشبعات المعيارية لمستويات كل اختبار فرعي باختبار الذاكرة العاملة

\begin{tabular}{|c|c|c|}
\hline التشبعات المعيارية & رقم المستوى & البعد \\
\hline$* .9 \mathrm{~V}$ & الأول & \\
\hline$* \ldots \leqslant V$ & الثاني & الذاكرة العاملة \\
\hline \% & الثالث & اللفظية \\
\hline$* \cdot \vee \vee \wedge$ & 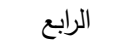 & \\
\hline *..Vr & الأول & \\
\hline *. . & الثاني & \\
\hline$* . v$. & الثالث & الذاكرة العاملة \\
\hline$* \cdot . \wedge \varepsilon$ & 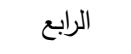 & البصرية-المكانية \\
\hline$* .91$ & الخامس & \\
\hline$* . \wedge 1$ & السادس & \\
\hline$* . .11$ & الأول & \\
\hline 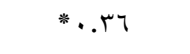 & الثاني & \\
\hline$* .0 r$ & الثالث & الذاكرة العاملة \\
\hline$* . . v$. & 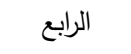 & المنفذة مركزيا \\
\hline$\div .91$ & الخامس & \\
\hline$* . \wedge 1$ & السادس & \\
\hline
\end{tabular}

حسـاب معاملات الصعوبة والتمييز لأسئلة الاختبارات الثلاثة المتضهنة باختبار الذاكرة العاملة ، وقد لوحظ أن معامـلات الصعوبة تراوحت وِّ اختبار الذاكرة العاملة اللفظية بين صفر وواحد ، ويخ اختبار الذاكرة العاملة البصرية

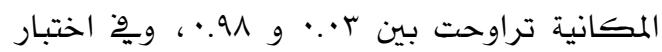
الذاكرة العاملة المنفذة مركزيا تراوحت بين (r ·.•وا ، ويمكن القول أن الأسئلة جاءت متدرجة من السهل إلى الصعب، وهذا ما هدفت إليه الدراسة عند بناء الاختبارات.
يعرض جدول ب نتائج مؤشرات حسن مطابقة النموذج التوكيدي لمكونات اختبار الذاكرة العاملة والقيم الحرجة المناظرة للحكم على حسن مطابقة النموذج. وأظهرت النتائج أن قيم جميع مؤشرات حسن المطابقة للنموذج تقع فِ نطاق القيم المقبولة. فكانت قيمة مربع كاي النسبي تساوي (عا.• ) وتعد هذه القيمة صغيرة جدا وأقل من 0، مها يشير إلى جودة عالية لملاءمة النهوذج مع البيانات حسب ما ذكره تيفزة (Y (Y). كما أظهرت النتائج أن قيم المؤشرات الإحصائية للنموذج تقع ِِّ مدى القيم المقبولة حسب ما ذكر مِّ المحرزي (ع ا•r) و (Sun, 2005). فقد كانت قيمة الجذر التربيعي المتوسطات مربعات الخطأ التقاربي (RMSEA) مساوية لـ ا•.• ، وقيمة الجذر التربيعي لمتوسطات مريعات الخطأ التقاربي (Standatdized RMR) مساوية لـ 11 •••، وقيمة مؤشر المطابقة المقارن (CFI) مساوية لـ V9. (NFI) (IFI) مساوية لـ V0.• . وتشير هذه المؤشرات إلى دعم بيانات الاختبار للبنية العاملية التي بني عليها المقياس وفقا لنموذج بادلي للذاكرة العاملة.

كما تم حساب تشبع الفقرات على مكونات الذاكرة العاملة من خلال قيم التشبعات المعيارية، وجاءت كلها عالية ودالة إحصائيا كها يظهر وِ2 جدول ب. حساب الإحصاءات الوصفية والمتمثلة وِّة المتوسطات الحسابية والانحرافات المعيارية لدرجات الطلبة پِّ كل اختبار فرعي من اختبار الذاكرة العاملة، ويوضح جدول ع المتوسطات الحسابية والانحرافات المعيارية للاختبارات الفرعية الثلاثة حسب متغير النوع والصف الدراسي. تظهر النتائج أن متوسطات درجات الطلبة بالاختبارات الفرعية الثلاثة تختلف باختلاف الصف الدراسي، حيث كان أقل متوسط حسابي لطلبة الصف الخامس، وازداد متوسط درجات الطلبة بالتقدم بالصف الدراسي ليكون أعلى متوسط حسابي لدرجات طلبة الصف 
جدول ؛

المتوسطات الحسابية والانحرافات المعيارية للاختبارات الفرعية الثلاثة حسب متغيري النوع والصف الدارسي

\begin{tabular}{|c|c|c|c|c|c|}
\hline \multirow{2}{*}{ الاجمالي } & \multicolumn{3}{|c|}{ الصفوف } & \multirow{2}{*}{ الجنس الجن } & \multirow{2}{*}{ مكونات الذاكرة العاملة } \\
\hline & سابع & سادس & خامس & & \\
\hline (1.77) V.r. & $(1.7 \cdot)^{\wedge} \wedge . \cdot 7$ & $(1 . \Sigma Y) V . r T$ & $(1.91)$ 7.8. & ذكور & \multirow{3}{*}{ 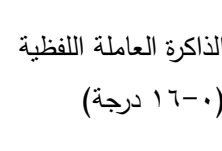 } \\
\hline$(1 . \wedge 9)$ V.or & $(r . . r) \wedge .1 r$ & $(1 .\{\Lambda) \vee .17$ & $(Y . I Y) V . r V$ & 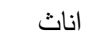 & \\
\hline$(1 . \vee \wedge) \vee . \varepsilon \varepsilon$ & $(1 . \wedge r) \wedge . .9$ & $(1 . \leqslant 0)$ V.r & $(r . . r) ~ T .99$ & اجمالي & \\
\hline$(\lceil\ldots) \wedge . \leqslant 0$ & (r..0) $9.4 \%$ & $(r .1 v) \wedge .97$ & $\left(Y . V_{0}\right) V_{. .}$ & ذكور & الذاكرة العاملة \\
\hline$(r . r v)$ 9.rV & r... & (T.Tr) & $(r . \wedge r) \wedge . \neg r$ & اناث ل & البصرية-المكانية \\
\hline$(\Upsilon .19) \wedge . \wedge 7$ & (T.TT) $9 . \wedge \varepsilon$ & $(r . \Sigma 1) \wedge .91$ & $(r . \vee q) \vee . \wedge r$ & اجمالي & (· - \\
\hline$(T . V \varepsilon) 11 . \wedge v$ & 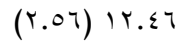 & $(Y .00)$ I Y... & $(r . . \wedge) 11.1 \mathrm{r}$ & ذكور & الذاكرة العاملة المنفذة \\
\hline$(r . .0), r .99$ & $(r . \leq \Gamma) 1 r .9 \leq$ & (r.01) Ir.Ar & (r.I $)$ IT.Kr & اناث & 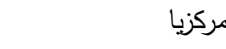 \\
\hline$(r . q \cdot)$ I T. $\varepsilon r$ & $(r . \cdot r)$ Ir.r. & $(r .0 r)$ M. Y. $\Sigma T$ & $(5.19) 11.7 \mathrm{~V}$ & اجمالي & (· - > درجة) \\
\hline
\end{tabular}

بلغ عددهـم (•ع) طالبا وطالبة تم اختيارهم بطريقة

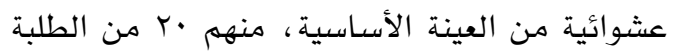
الذكور و •r من الطلبة الإناث من مدارس مختلفة ، وتم حساب العلاقة الإرتباطية بين درجات الاختبارين لنفس المجهوعة من الطلبة باستخدام معامل ارتباط بيرسون، وكانت قيمة معامل الصدق التلازمي

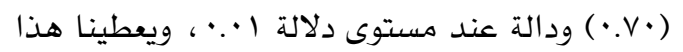
مؤشرا على تمتع اختبار الذاكرة العاملة ٌِِ هذه الدراسـة بصدق نتائجها.

الصدق التببؤي (Predictive Validity) وللتحق من الصدق التبؤي لاختبار الذاكرة العاملة تم دراسة العلاقة بين درجاته ودرجات التحصيل الدراسي للطلبة يخ المواد التالية: (التربية الإسـلامية، اللفة العربية، الرياضيات، العلوم، الدراسـات الاجتهاعية). وقد تم اختيار هذه المواد لأهميتها، حيث تعطى النصيب الأكبر من عدد الحصص التي تدرس للطلبة وِّ جدول المدرسة. و تم دراسـة العلاقة

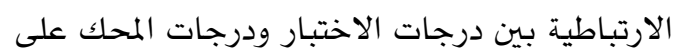
العينة الأساسية باستخدام معامل ارتباط بيرسون، وأظهرت النتائج تمتع الاختبار بصدق تتبؤي متوسط مع كل من التحصيل الدراسي يخ التربية الإسـلامية

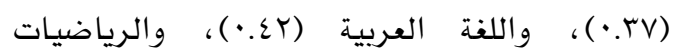

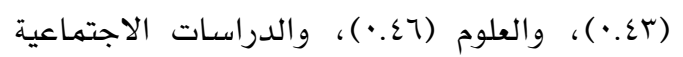
(rع.•). وكانت جميع معامـلات الارتباط دالة عند

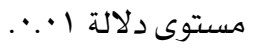

بالنسبة لمعامـلات تهييز الأسئلة، أظهرت النتائج أن معاملات تمييز الأسئلة ِِّْ اختبار الذاكرة العاملة

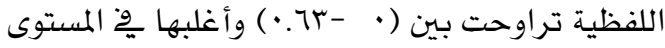
المقبول لتمييز الأسئلة، فالأسئلة التي حصلت على معاهل تهييز صفر كانت السؤال الأول ِِّ الاختبار (جميع الطلبة أجابوا عليه إجابة صحيحة) والأسئلة

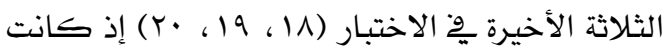
إجابات جميع الطلبة على هذه الأسئلة خطأ. كما تراوحت معاملات تمييز الأسئلة وِّ اختبار الذاكرة العاملة البصرية - المكانية بين

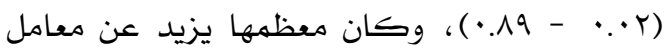
تمييز ع.•، مها يشير إلى مناسبة المفردات بالاختبار، كما تراوحت معاملات التمييز للأسئلة

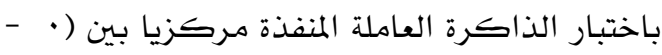

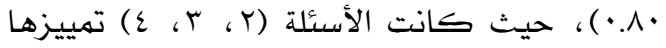
يساوي صفرا كون أن هذه الأسئلة كانت وِّ المستوى الأول فأجاب عنها جميع الطلبة، بينما كانت معامل التمييز لبقية الأسئلة عالي؛ مها يشير إلى مناسبة المفردات بالاختبار.

الصدق التلازمي: (Concurrent Validity) وللتحق من الصدق التحلازمي للاختبار فقد تم بتطبيق بطارية الذاكرة العاملة لسليمان (·• (†)

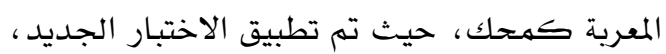
والاختبار المحك بالتزامن لذات العينة من الطلبة وقد 
نتائج السؤال الثالث: ما معايير تفسير درجات

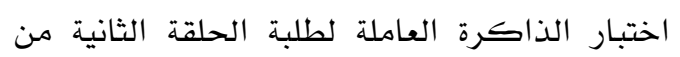

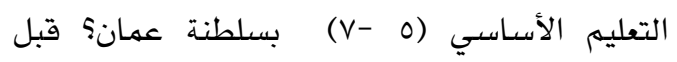
اشتقاق معايير تفسير الدرجات الخام ِِّ اختبارات الذاكرة العاملة، تم إجراء اختبار "ت" وتحليل

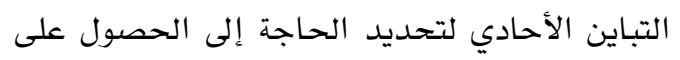

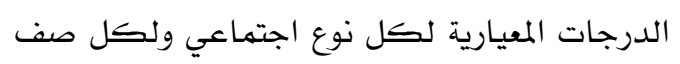
دراسي على حده من خلال اختبار فرضيات وجود فروق ذات دلالة إحصائية ِِخ الاختبارات الفرعية

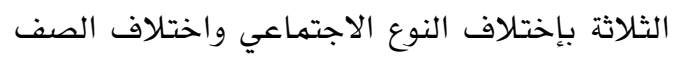

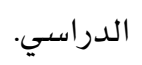

لم يظهر اختبار "ت" لمجهوعتين مستقلتين وجود

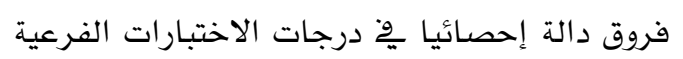
للذاكرة العاملة حسب النوع الاجتماعي للطلبة.

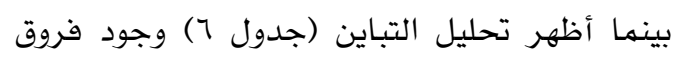
ذات دلالة إحصائية بين متوسطات درجات الطلبة وِ2

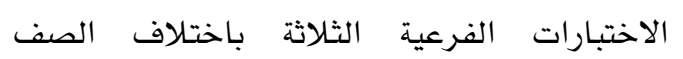

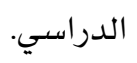
ولمعرفة اتجاه الفروق، تم استخدام اختبار (LSD) للمقارنات البعدية، ويوضح جدول V نتائج هذه المقارنات. وقد بينت النتائج ِوْ جدول V أن هناك فروقا ذات دلالة إحصائية عند مستوى دلالة 0..

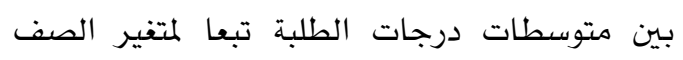

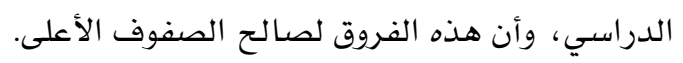
وبناء على النتائج السابقة، تم اشتقاق معايير صفية للطلبة، وذلك باستخدام الدرجات المعيارية التائية والرتب المئينية للدرجات الخام بالاختبارات الفرعية الثلاثة وللدرجات الخام باختبار الذاكرة العاملة لكل صف من الصفوف الدراسية.
نتائج السؤال الثاني: ما مؤشرات ثبات اختبار الذاكرة العاملة لدى طلبة الحلقة الثانية من التعليم

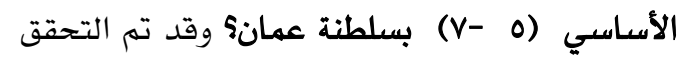

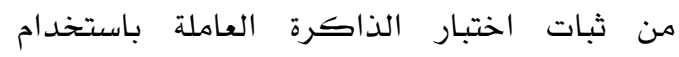

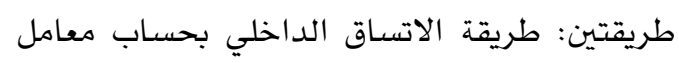

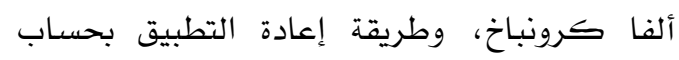
معامل الاستقرار.

\section{طريقة الاتساق الداخلي (معامل ألفا لكرونباخ):}

تم استخراج معامل الثبات باستخدام معادلة ألفا لكرونباخ كمؤشر على الاتساق الداخلي للاختبار، باستخدام بيانات العينة الرئيسية كها يظهر بِ جدول 0، وتراوحت معامـلات ثبات ألفا

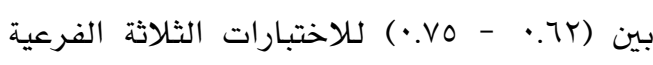
لجميع أفراد العينة، وتراوحت بين (ماO. · -17.• )

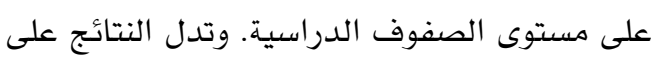
تمتع الاختبار بثبات اتسـاق داخلي جيد.

طريقة إعادة تطبيق الاختبار: Test-Retest) Method)

وللتحق من ثبات الاستقرار لدرجات الطلبة باختبار الذاكرة العاملة، تم تطبيق الاختبار على الطلبة مرتين وبفاصل زمني تراوح بين أسبوعين إلى ثلاثة أسابيع على عينة شملت (·r) طالبا وطالبة تم اختيارهم بطريقة عشوائية من العينة الأساسية. ويظهر جدول ه قيم معامـلات الاستقرار للاختبارات

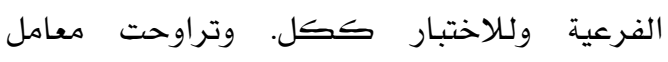
الاستقرار بين (Vo. - VO. ) للاختبارات الفرعية بينما كانت قيمته س V. • للاختبارات مجتمعة ، مها يشير أيضا إلى تمتع الاختبار بهعامل استقرار مقبول

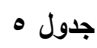

قيم معاملات الاتساق الداخلي وقيم معاملات الاستقرار لاختبارات الذاكرة العاملة حسب الصفوف الثلاثة

\begin{tabular}{|c|c|c|c|c|c|c|}
\hline \multirow{3}{*}{ الصابع } & \multicolumn{2}{|c|}{ معامل ألفا كرونباخ } & \multirow{3}{*}{ ككل } & \multirow{3}{*}{ للصفوف كعل الاستقرار } & \multirow{3}{*}{ الأسئلة } & \multirow{3}{*}{ الاختبار } \\
\hline & الصف & الصف & & & & \\
\hline & السادس & 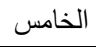 & & & & \\
\hline . & $.0 \%$ & 每 & איד & .ro & 17 & الذاكرة العاملة اللفظية \\
\hline$\cdot . \wedge$ &..$\vee 4$ &..$\vee 4$ &.$\vee 99$ &. Vo & $r \varepsilon$ & الذاكرة العاملة البصرية-المكانية \\
\hline..$\vee 9$ &. .74 & $\cdot \vee \wedge \wedge$ & .100 &. .01 & $r \varepsilon$ & الذاكرة العاملة المنفذة مركزيا \\
\hline
\end{tabular}


جدول 1

تحليل التباين الأحادي لاختبارات الذاكرة العاملة وفقا لمتغير الصف الدراسي

\begin{tabular}{|c|c|c|c|c|c|c|}
\hline الاحتمالية & قيمة (ف) & المتوسط & الحرية & المجربعات & مصدر التباين & الاختبار \\
\hline \multirow[t]{2}{*}{$\ldots \cdots$} & \multirow[t]{2}{*}{ V.VT } & $r \varepsilon .97$ & r & $\leq 9.94$ & بين المجموعات & \multirow{2}{*}{ الذاكرة العاملة اللفظية } \\
\hline & & r.r. & rqV & $900 . . r$ & داخل المجموعات & \\
\hline \multirow[t]{2}{*}{$\cdots+1$} & \multirow[t]{2}{*}{ R.It } & $11 \cdot .1$ & r & $r r \ldots r$ & بين المجموعات & \multirow{2}{*}{ الذاكرة العاملة البصرية- } \\
\hline & & $10 . \leqslant 0$ & rqV & $\leqslant 0 \wedge 9.97$ & داخل المجموعات & \\
\hline \multirow[t]{2}{*}{$\cdots \cdots 1$} & \multirow[t]{2}{*}{$7 . V 7$} & ON.0Y & r & $118 . .0$ & بين المجموعات & \multirow{2}{*}{ مركزيا الذرة العاملة المنفذة } \\
\hline & & 1.77 & rqv & TOVY.T. & داخل المجموعات & \\
\hline
\end{tabular}

جدول

نتائج اختبار (LSD) للمقارنات البعدية بين متوسطات درجات الطلبة على الاختبارات الفرعية الثلاثة في الصفوف V

المختلفة

\begin{tabular}{|c|c|c|c|c|}
\hline \multirow{2}{*}{ لصالح الصف السادس اتجاه الفروق } & \multirow{2}{*}{ 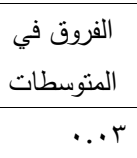 } & \multicolumn{2}{|c|}{ المقارنات الثنائية } & \multirow{2}{*}{ الاستدعاء السمعي الاختبار } \\
\hline & & الصف السادس & الصف الخامس & \\
\hline لصالح الصف السابع & $* . . \wedge$ & الصف السابع & & \\
\hline لصالح الصف السابع & $\% .10$ & صف السابع & الصف السادس & \\
\hline لصالح الصف السادس & $* 1.0$ & صف السادس & الصف الخامس & الثكل المختلف \\
\hline لصالح الصف السابع & $* r . . r$ & الصف السابع & & \\
\hline لصالح الصف السابع & $.0 Y$ & الصف السابع & الصف السادس & \\
\hline لصالح الصف السادس &.$v 4$ & الصف الساد & الصف الخامس & لون الحبر \\
\hline لصالح الصف السابع & $* 1.0 r$ & الصف السابع & & \\
\hline لصالح الصف السابع &.$V V$ & الصف السابع & الصف السادس & \\
\hline
\end{tabular}

تم استخدام اختبار الاستدعاء السمعي لقياس الذاكرة العاملة اللفظية واختبار الشكل المختلف

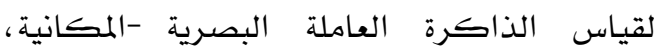
واختبار لون الحبر لقياس الذاكرة العاملة المنفذة مركزيا. وأظهرت نتائج الدراسـة صلاحية اختبارات الذاكرة

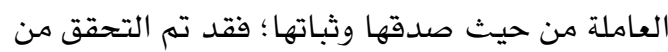
أربعة مؤشـرات لصدق اختبار الذاكرة العاملة وهي: الصدق الظاهري (صدق المحكهمين)، الصدق البنائي، والصدق التلازمي والصدق التتبؤي، وأظهرت نسب اتفاق المحكهمين على الاختبارات المتضهنة المرتفعة مؤشرا على الصدق الظاهري للاختبارات، واتفقت هذه النتائج مع كل من دراسة

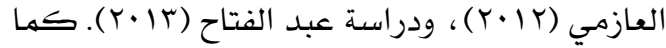
أظهر التحليل التوكيدي العاملي صدق البناء العاملي للاختبار وقدرة الاختبارات على التمييز بين

\section{مناقشة النتائج}

سعت الدراسة إلى توفير اختبار لقياس ثثلاثة مكونات للذاكرة العاملة حسب نهوذج بادلي وتقنينها على طلبة الصفوف الخامس والسـادس والسابع 2ِخ سلطنة عمان، ويعد قياس الذاكرة العاملة للطلبة ِِّْ هذه المرحلة العمرية والدراسية مهما وذلك للدور الكبير الذي تلعبه الذاكرة

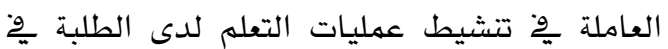
مختلف المواد الدراسية، وتشهل المكونات الثلاثة للذاكرة العاملة حسب نهوذج بادلي (الذاكرة العاملة اللفظية، الذاكرة العاملة البصرية - لبكية المكانية، الذاكرة العاملة المنفذة مركزيا) عمليات التعلم الرئيسية اللازمة لاكتسـاب المعارف والمهارات وِّ المواد الدراسية والتي تعتمد ِِّ تدريسها على اللغة اللفظية واللغة البصرية واللفة الفراغية المكانية والقدرة على الربط بينهما مركزيا. وقد 
الحالية والتي كانت قيمتها (ro.•) لتعدد مصادر أخطاء القياس وِّ تطبيق الاختبار والتي تؤثر على ولى قيمة معامل الثبات كإختلاف الفاحصسين فِّ مرات التطبيق، حيث أن الاختبار يقدم بشكل سهعي

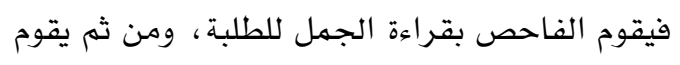
الطالب باستدعاء الكلمات الأخيرة وبالتالي

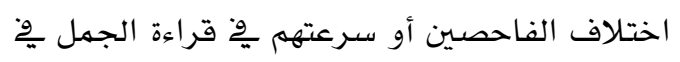
التطبيق الثاني قد يكون أثر ِِّ النتائج.

اختتهت الدراسة بحساب الدرجات المعيارية التائية والرتب المئينية من خلال منحها معنى" للدرجات

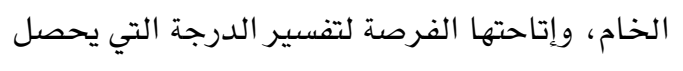
عليها الطالب، فتقدم ميزانا يحدد مستوى أداء

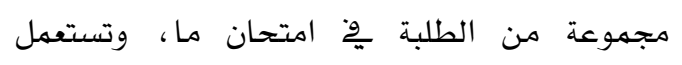
للحكم على مستوى أداء أي طالب بالنسبة لأداء المجموعة التي ينتهي إليها. وتعد الرتب المئينية من أكثر المعايير استخداما حيث أنها تقدم صورة واضحة وسهلة وِّ تحديد مكان الفرد النسبي بين أقرانه من خلال النسبة المئوية للطلبة الذين يقل مستواهم عن الطالب، وقد تم اشتقاق الدرجات المعيارية لكل صف دراسي على حده بناء على

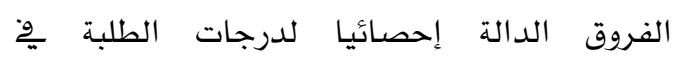

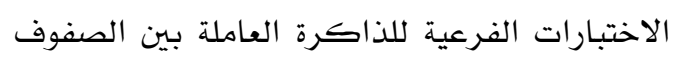

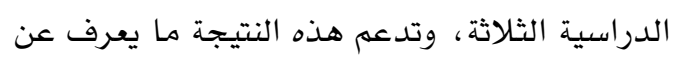

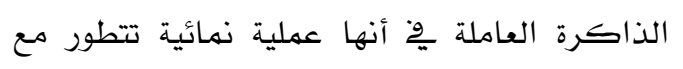
التقدم پِّ العمر حسب ما أظهرته دراسـات عديدة

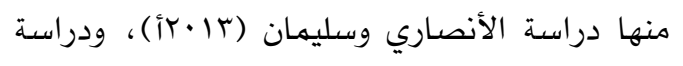

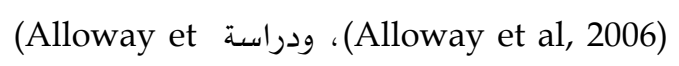
بينما له تظهر النتائج وجود اختلاف بين (al, 2004)

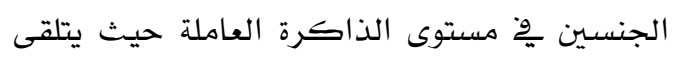

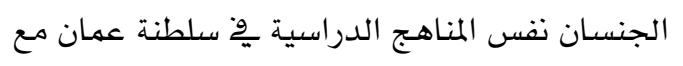
تشابه مدراس الجنسين وِّ الأجهزة والأدوات وطرائق إعداد المعلمـين واستخدامهم لاستراتيجيات تدريسية متقاربة.

\section{التوصيات والمقترحات}

ِّْ ضوء النتائج التي تم التوصل إليها ، توصي

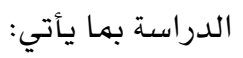

المكونات الثلاثة للذاكرة العاملة حسب نموذج بادلي. وقد اتفقت نتائج الدراسة مع كل من الان الأنصاري وسليمان (rالباب)، ودراسـة عبد الفتاح

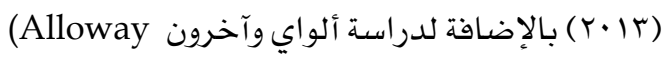

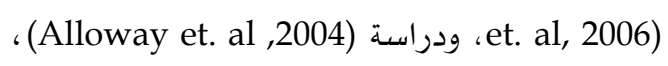

ودراسة جيوفور وآخرون (2013, Giofre et. al). كها أظهرت نتائج الصدق التلازمي قدرة اختبار

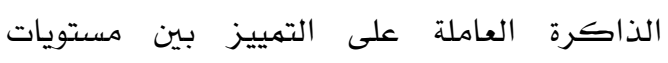
الذاكرة العاملة لدى الطلبة بهقادير مشابهة لاختبارات الذاكرة العاملة المعرية لسليهان

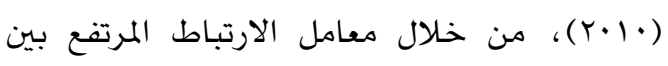
درجات كل منهما (معامل ارتباط= •V.•). وأظهرت النتائج قدرة اختبار الذاكرة العاملة على التنبؤ بالتحصيل الدراسي للطلبة ِّ عدد من المواد

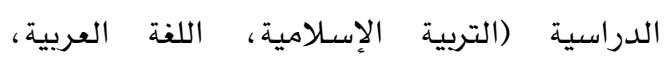

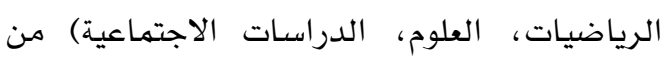
خلال وجود علاقة ارتباطية طردية متوسطة نسبيا بين اختبار الذاكرة العاملة والدرجات التحصيلية

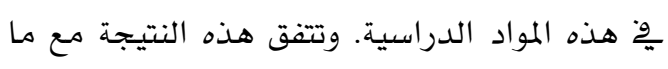
توصلت لله دراسة (Yguchi, 2008)، ودراسة عبد

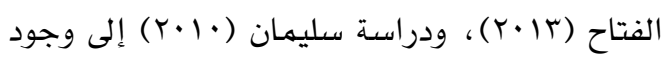
ارتباط إيجابي ودال بين درجات الطلبة باختبارات

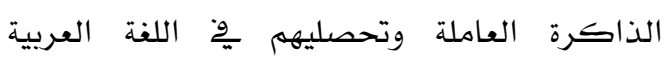
والرياضيات.

بالنسبة لثبات اختبار الذاكرة العاملة، أظهرت النتائج تهتع الاختبارات الفرعية بهعاملات اتسـاق داخلي عالية بحساب قيم معامل ثبات ألفا كرونباخ (تراوحت بين ب7.·- -17. • ) . كمها أظهرت درجات

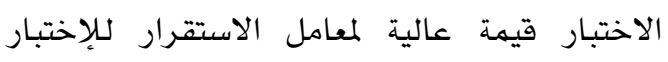
ككل حيث جاءت مساوية ل(T/.) ، وتتفق هذه النتيجة مع نتائج ثبات اختبارات أخرى للذاكرة

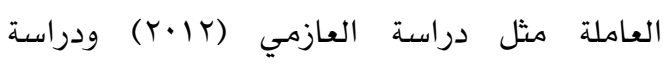
الأنصاري وسليمان (rا•rب). كها تراوحت قيم معامل الاستقرار للاختبارات الفرعية الثلاثة بين

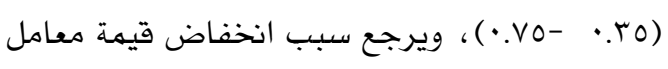

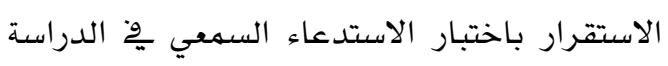


العاملة لدى الأطفال الكويتيين من ع و حتى با

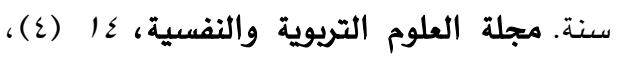
$.1 \% \Lambda-1 \cdot r$

الأنصاري، بدر محمد؛ وسليمان، عبدربه مغازي

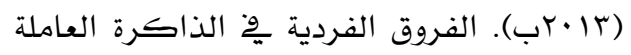
لدى الأطفال الكويتيين من عمر ع وحتى الهروالهرديه

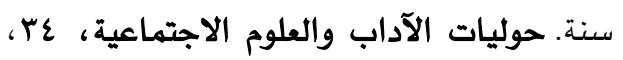
$.1 \cdot Y-V$

تيغزة، أحمد (r/ץ). التحليل العاملي الاستكشايخ مفاهيمهما ومنهجيتهما بتوظيف حزمة SPSS وليزدل. عمان: دار المسيرة للنشر والتوزيع. الحساني، سـامر (11) (1). أثر برناهـ تدريبي

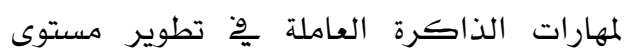
الاستيعاب القرائي لدى الطلبة ذوي مشكلات

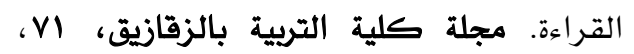
$.907-191$ راشد، عدنان غائب (ع). الاضطرابات الاتفعالية عند الأطفال. مجلة الطفولة والتمية، التهاب $.19 \varepsilon-11 \mathrm{~V} ،(10) \varepsilon$

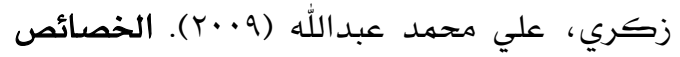
السيكومترية لاختبار أوتيس - لينون للقدرة العقلية مقدرة وفق للقياس الكلاسيكي ونموذج راش لدى طلبة المرحلة المتوسطة بمحافظة صبيا التعليمية. رسالة ماجستير غير منشورة ، جامعة أم القرى، السعودية.

الزيات، فتحي مصطفى (1991) ). الأسس البيولوجية والنفسية للنشاط العقلي المعربِّ. القاهرة: دار النشر للجامعات.

سليمان، عبد ربه مغازي (·(Y). دور الذاكرة

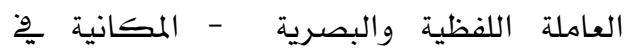
التحصيل الدراسي لدى تلاميذ التعليم الأسـاسي.

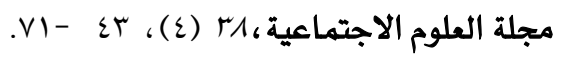

1. استخدام اختبار الذاكرة العاملة المعد ِِّ

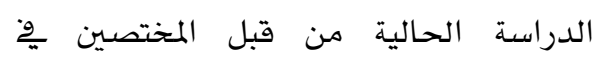

المديريات التربوية العامة التابعة لوزارة التربية والتعليم، والمعلمـين بمدارس الحلقة الثانية من التعليم الأسـاسي مِ تشخيص مكونات الذاكرة العاملة المختلفة لطلبة الصفوف الصفال

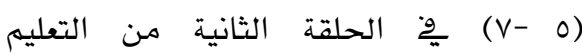
الأسـاسي.

r. استخدام اختبار الذاكرة العاملة ِِّ تشخيص مكونات الذاكرة العاملة لدى عينات مختلفة

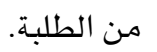

r. عقد برامج تدريبية لتدريب المختصسين وِ

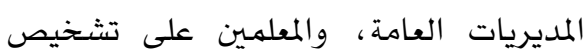
مكونات الذاكرة العاملة لدى الطلبة باستخدام اختبار الذاكرة العاملة.

ع. تطوير اختبار الذاكرة العاملة ليشمل مكونات أخرى جديدة للذاكرة العاملة. 0. الاستفادة من اختبار الذاكرة العاملة ِّ إجراء دراسـات لاحقة للكشف عن مستوى الذاكرة العاملة لدى الطلبة، ودور المناهـج الدراسية فِخ تطويرهـا. المراجع

\section{References}

إبراهيم، سليمان عبد الواحد يوسف (·+ (†). الذاكرة الإنسانية لدى المتعثرين دراسيا. القاهرة: إيتراك للطباعة والنشر والتوزيع.

أبو الديار، مسعد (Y|+ץ). الذاكرة العاملة وصعوبات التعلم. الكويت: مركز تقويم وتعليم

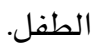

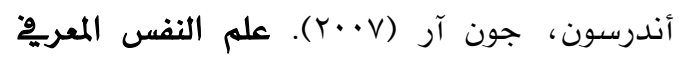
وتطبيقاته. ترجمة محمد صبري سعيد. عمان:

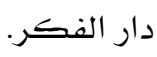
الأنصاري، بدر محمد؛؛وسليمان، عبد ربه مغازي (با.بأ). النمذجة البنائية لمكونات الذاكرة 


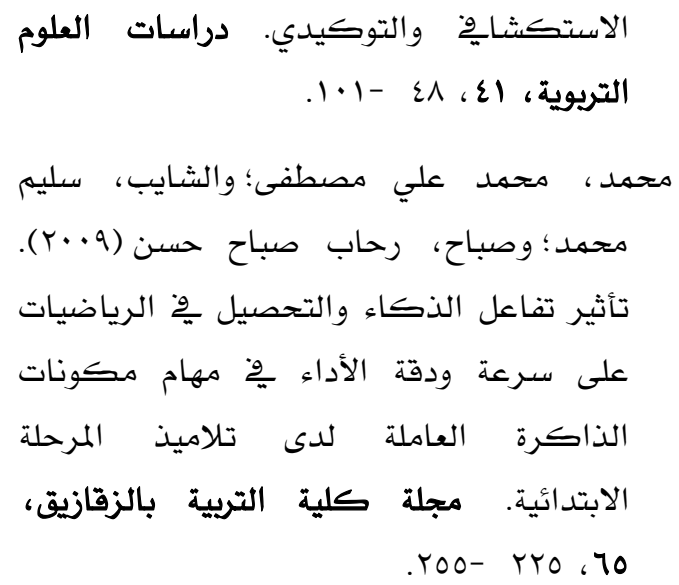

Alloway, T. (2007). Working memory, reading and mathematical skills in children with developmental coordination disorder. Experimental Child Psychology,96 (1), 20-36.

Alloway,T., Gathercole, E., \& Pickering (2006). Verbal and visuo-spatial shortterm and working memory in children: are they separable? Child Development, 77 (6), 1698-1716.

Alloway,T., Gathercole, E., Willi, C, \& Adams, A. (2004). Asteuctural analysis of working memory and related cognitive skills in young children. Journal of Experimental Child Psychology, 87 (2), 85-106.

Baddeley, A (1992). Working memory. Scince, 225 (1), 556-559.

Baddeley, A. D. (2000). The episodic buffer: A new component of working memory. Trends in Cognitive Sciences, 4 (11), 417-423.

Baddeley, A. D. (2002A). Is working memory still working?. European Psychologist, 7 (2), 85-97.

Baddeley, A. D. (2002B).Fractionating the central excuctive. New Yourk: Oxford University Press.

Baddeley, A. D. (2003). Working memory: Looking back and looking forward. Nature Review, Neuroscience, 4, 829-839.

Baddeley, A. D. \& Hitch, G. J. (1974). Working memory. Recent Advances in Learning and Motivation, 8, 47-89.

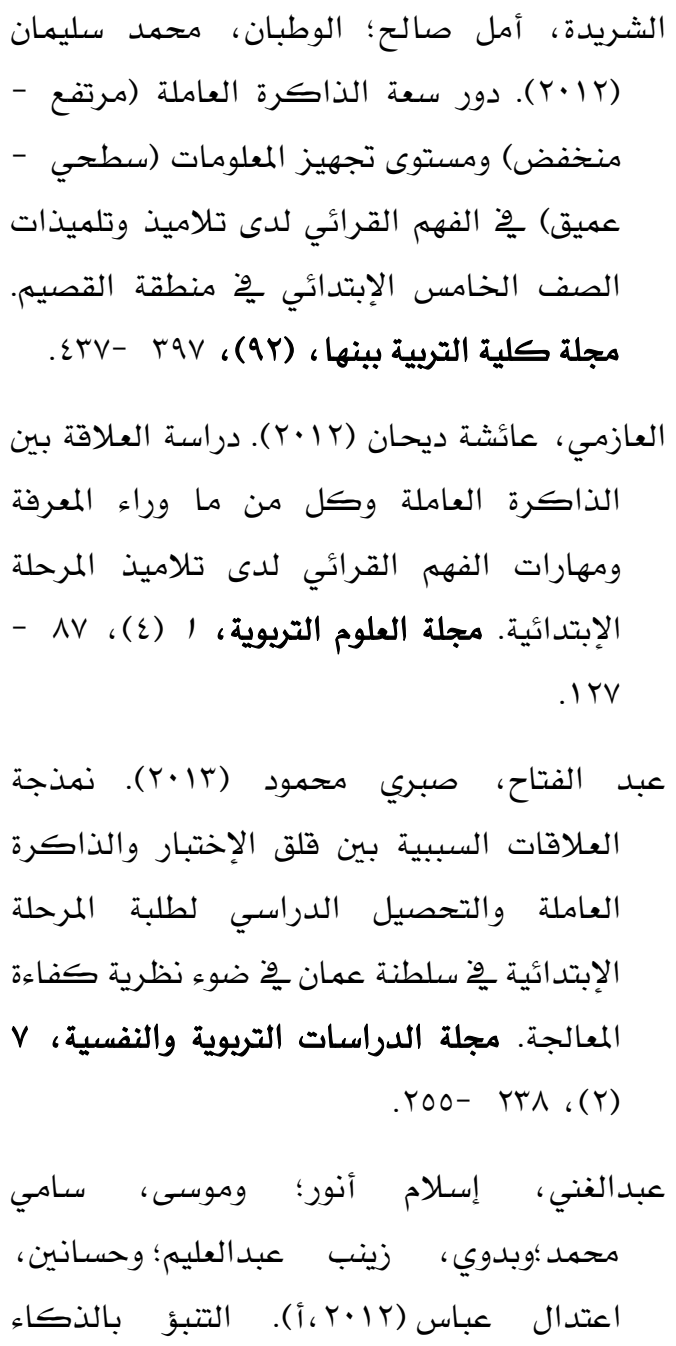


Baddeley, A.D; Hitch, G.J; Allen, R.J (2009). Working memory and binding in sentence recall. Journal of Memory and Language, 61, 438-456.

Gathercole, S. E.(2004). Working memory \& learning during the school years. Procedings of The British Academy, 125, 365-380.

Giofre,D., Mammarella,C. \& Cornoldi,C.(2013).The structure of working memory and how it relates to intelligence in children. Intelligence, 41, 396-406.

Pickering, J., \& Gathercole, E. (2001). Working memory test battery for children. Retrieved 21/9/2014, from: http://www.innovact.co.za

Sun, J. (2005). Assessing goodnees of fit in confirmatory factor analysis. Measurement and Evaluation in Counsling and Development, 37, 240-256.

Van Der Molen, J. (2010). Working memory structure in 10 and 15 year old children with mild to borderline intelleectual disabilities. Research in Development Disabilities, 31 (6), 12581263. 